\title{
Sexual coercion and reproductive health: A focus on research
}

Lori L. Heise

Kirsten Moore

Population Council

Nahid Toubia

Follow this and additional works at: https://knowledgecommons.popcouncil.org/departments_sbsr-rh

Part of the Demography, Population, and Ecology Commons, Domestic and Intimate Partner Violence Commons, Family, Life Course, and Society Commons, International Public Health Commons, and the Women's Health Commons

How does access to this work benefit you? Let us know!

\section{Recommended Citation}

Heise, Lori L., Kirsten Moore, and Nahid Toubia. 1995. "Sexual coercion and reproductive health: A focus on research." New York: Population Council. 


\section{Sexual Coercion and Reproductive Health,}

\section{A focus on Research}

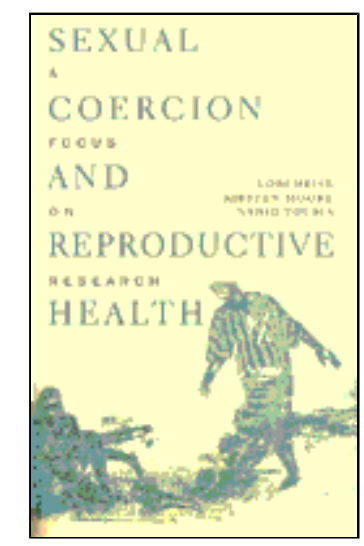

FOREWARD

INTRODUCTION

\section{DEFINING THE LINKS}

2. MEN'S VIOLENCE: ORIGINS, MYTHS, AND SCIENCE

\section{RESEARCH ISSUES AND METHODOLOGY}

\author{
Lori Heise \\ Kristen Moore \\ Nahid Toubia
}

\section{RECOMMENDATIONS}

\section{APPENDICES}

LORI HEISE is Co-Director of the Health and Development Policy Project.

\section{LIST OF PARTICIPANTS}

KIRSTEN MOORE is Program Manager of Gender, Family and Development at the Population Council.

\section{BIBLIOGRAPHY}

NAHID TOUBIAis Executive Director of RAINBOW (Research, Action \& Information Network for Bodily Integrity of Women), 915 Broadway, Suite 1603, New York, New York 100 10. 1

THE POPULATION COUNCIL seeks to improve the wellbeing and reproductive health of current and future generations around the world and to help achieve a humane, equitable, and sustainable balance between people and resources. The Council, a nonprofit,

nongovernmental research organization established in 1952, has a multinational Board of Trustees; its New York headquarters supports a global network of regional and country offices.

THE POPULATION COUNCIL

One Dag Hammarskjold Plaza

New York, NY 10017 TEL: 212-339-0500

FAX: 212-755-6052

email:pubinfo@popcouncil.org

THE HEALTH AND DEVELOPMENT POLICY PROJECT works to promote women's health and well-being by raising awareness of the gender and social justice dimensions of population and macroeconomic policies and by integrating women's needs and perspectives into international health policy and practice.

HEALTH AND DEVELOPMENT POLICY PROJECT

6930 Carroll Avenue,Suite 430

Takoma Park, MD 20912

TEL: 301-270-1182

FAX: 301-270-2052

email:hdpp@igc.apc.org

Revised edition copyright (C) 1995 by the Population Council, Inc.

\title{
THE POPULATION COUNCIL LIBRARY CATALOGING DATA
}

\author{
Sexual coercion and reproductive health: \\ a focus on research / by Lori Heise, \\ Kirsten Moore [and] Nahid Toubia. \\ New York: Population Council. 1995. 59 p. \\ 1. Sexual harassment of women. I. Heise, Lori. \\ II. Moore, Kirsten. III. Toubia, Nahid. \\ HV6556.S6 1995
}

Any part of this report may be copied or adapted to meet local needs without permission from the authors or the Population Council, provided that the parts copied are distributed free or at cost (not for profit). Any commercial

reproduction requires prior permission from the Population Council. The authors would appreciate receiving a copy of any materials in which the text or figures in the report are used. 


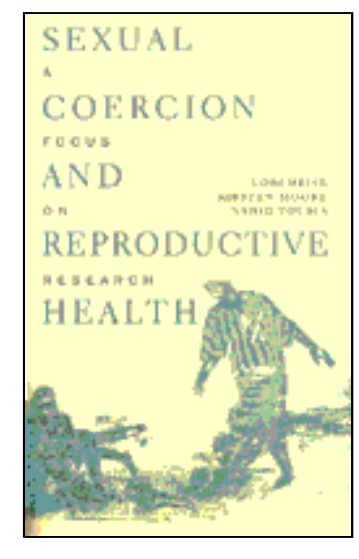

This publication concerns a subject we all wish would go away: physical and sexual abuse. It is a subject ignored or denied in most societies and neglected by health professionals and researchers. But genderbased violence persists in almost all societies, and, in some, it is on the increase.

We hope this report will be useful to those in the family planning/reproductive health field who desire to conduct research or implement programs to address sexual violence and its impact on women's reproductive health. We also hope the report contributes to a better understanding of the context of sexual coercion as well as its causes and consequences. Most of all, we hope this publication successfully makes the argument that sexual coercion is something that reproductive health practitioners and researchers can and should do something about.

The ideas presented herein are derived largely, although not exclusively, from a two-day meeting jointly organized by the Ebert Program in Reproductive Health of the Population Council and the Health and Development Policy Project. We supplemented the meeting discussions with relevant written material, giving emphasis to literature published by meeting participants.

We are indebted to the many participants who were willing to speak candidly about their own personal frustrations and learning experiences. We are also grateful for the care and consideration that everyone demonstrated for the women with whom they work. Clearly those who participated in this seminar share a deep commitment to eradicating sexual coercion -a fact that gives hope that we can, as individuals and as a community, make an important difference to women's lives.

We wish to thank Kirsten Moore, Program Manager with the Population Council's Gender, Family and Development Program, for her insight and perseverance In compiling a first draft of this report We also acknowledge the generous support of the John D. an Catherine T. MacArthur Foundation in financing the meeting upon which this report is based, as well as the ongoing support of the For and MacArthur Foundations to both the Ebert Program of the Population Council and the Violence, Health, and Development Program. Additionally, the Ebert Program would like to acknowledge the core support it receives from the Rockefeller Foundation; and the Health and Development Policy Project acknowledges the core support it receives from the Shaler Adams Foundation and the Moriah Fund

\section{DEFINING THE LINKS}

2. MEN'S VIOLENCE: ORIGINS, MYTHS, AND SCIENCE

\section{RESEARCH ISSUES} AND METHODOLOGY

4.RECOMMENDATIONS

APPENDICES

LIST OF PARTICIPANTS

BIBLIOGRAPHY 
and girls are often vulnerable to abuse does not mean that all women are powerless. Women have demonstrated an incredible capacity for agency and resourcefulness even in the face of the most constrained social conditions.

However, women deserve broader choices and the basic right to be safe and free from violence. We should also remember that women are not just victims, but survivors and ultimately agents of change.

Second, we must bear in mind that although men commit the majority of abuse against women, not all men are violent. As professionals and activists, we need to create coalitions between men and women to eradicate all forms of violence and abuse. For most women, men are fathers, sons and partners in life. In raising these difficult issues, we seek to equalize and improve partnerships, not to point blame or promote antagonism between men and women.

\section{-LORI HEISE}

-NAHID TOUBIA

Back || Forward 


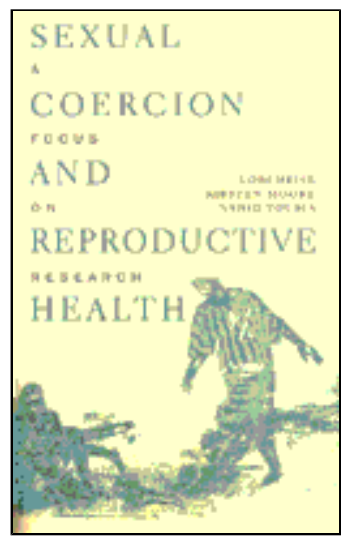

Sometime around 1990, the subject of violence against women gained prominence as an issue of international concern. For the first time, the long-lived reality of women's and girls' vulnerability to abuse by states, communities, families and intimate partners became the focus of widespread international debate. Major institutions -such as the United Nations' General Assembly, the Pan American Health Organization and the Organization of American States -recognized the gravity of gender-based abuse and passed resolutions condemning it. A coalition of more than 900 international women's groups won recognition of violence against women as a violation of women's human rights at the Second World Conference on Human Rights held in Vienna in June 1993. Further, the Global Commission on Women's Health identified gender-based violence as one of its priority themes. Finally, international organizations heard the demands expressed by grassroots women's groups during two decades of activism.

Those working to improve the legal, economic and social standing of women around the world have met these international developments with enthusiasm. Yet, despite a shared sense of sympathy and moral outrage against violence, different sectors have exhibited a limited willingness and ability to take action on gender-based abuse. Too often, activists hear the refrain of "yes, we know this happens," or 11 yes, this is horrible, but what can we do about it?"

For the most part, those in the field of family planning and reproductive health have reacted this way. Most family planning practitioners have expressed real doubts about their ability to address issues of power, and more specifically, coercion and abuse, within the scope of their work. Others have questioned the relevance of violence to the field of reproductive health at all.

Yet a growing body of literature documents that genderbased abuse may be linked to some of the most intractable reproductive health issues of our time: teenage pregnancy, high-risk sexual behavior (such as unprotected sex with multiple partners and prostitution), sexually transmitted diseases (STDs), neonatal and maternal mortality and chronic pelvic pain. In addition, there is a growing consensus among scholars, jurists and human rights activists that family planning/reproductive health services are a logical point to identify and provide referrals to women in need of social or legal services precisely because health clinics are one of the few institutions that regularly have contact with women.

To better inform efforts to integrate concerns with genderbased abuse with family planning/reproductive health, the
2. MEN'S VIOLENCE: ORIGINS, MYTHS, AND SCIENCE

3. RESEARCH ISSUES AND METHODOLOGY

4.RECOMMENDATIONS

APPENDICES

LIST OF PARTICIPANTS

BIBLIOGRAPHY 
Population Council's Robert H. Ebert Program on Critical Issues in Reproductive Health combined forces with the Health and Development Policy Project to coordinate a seminar on sexual coercion and women's reproductive health with a focus on research. From November 22 to 23, 1993 about 50 researchers, activists and reproductive health practitioners gathered in Mew York to share experiences and develop strategies to better document, understand and address the causes and consequences of gender-based abuse.

Through a series of panel presentations, small group discussions and working sessions, the seminar sought to build upon the research and practical experiences of individuals from a variety of disciplines -- medical, legal, human rights, social activism, development, public health and anthropology-- to develop a family planning/reproductive health research and action agenda on the effects of sexual coercion on women's reproductive health. A related objective was to bring together, for the first time, researchers who have worked in the area of sexual violence, often in isolation, to share their findings and approaches to their work.

This report is a synthesis of a very rich and productive exchange. The first chapter documents the connection between coercion and reproductive health with some of the research and practical experiences of those attending the workshop. This section explores the multifaceted context and consequences of coercive sex for women's reproductive health, as well as the direct and indirect implications for family planning/ reproductive health services.

The second part of the report looks at what we do and do not know about the origins of sexual aggression among men. Which behaviors are the result of biological destiny, which are shaped by culture, and, most importantly, what is changeable?

The third section concentrates on research issues and methodology. What have we determined so far? What are the limitations of our knowledge? Much of the discussion in the workshop focused on ways to make the research process more relevant to the outcomes we would like to achieve.

The final section of the document includes a list of recommendations developed by the participants for future work on sexual coercion in the family planning/reproductive health arena. 


\section{Chapter 1}

\section{Defining the links}

IN HER OPENING PRESENTATION, NAHID TOUBIA of the Population Council described how women's activism against violence has encouraged institutions like the Population Council to begin exploring the impact of violence on women's reproductive health.

Gender-based abuse crosses the boundaries of class, education, culture and ethnicity and, as defined here, primarily involves the physical or psychological abuse of women or young girls. It takes a variety of forms-from social indoctrination that compels women to cut their genitals to gain social acceptance to overt acts of force, such as rape.

\section{By way of definition}

For the purposes of this report, sexual coercion is the act of forcing (or attempting to force) another individual through violence, threats, verbal insistance, deception, cultural expectations or economic circumstance to engage in sexual behavior against his or her will. As such it includes a wide range of behaviors from violent forcible rape to more contested areas such as cultural expectations that require young women to marry and sexually service men not of their choosing. The touchstone of coercion is an individual woman's lack of choice to pursue other options without severe social or physical consequences.

Violence and the fear it engenders affects women's lives in many ways. To begin building a common language and conceptual frame, Nahid led the seminar in a simple brainstorming exercise: What are the ways that violence affects women's sexual and reproductive lives?

This exercise yielded a long, complex list of associations between physical and sexual abuse and various negative health outcomes (see Box 1). Among the direct reproductive health impacts of violence were STDs, unwanted pregnancy, miscarriage, unsafe abortion, as well as homicide and suicide of women in cultures where rape and/or unwed pregnancy are highly stigmatized. Further, coercion and lack of negotiating power in relationships also indirectly put women's health at risk-by limiting their ability to use birth control, for example, or prohibiting them from seeking medical care without their partner's permission. Finally, the group included examples of how the health care system itself can turn violent, through abusive and humiliating treatment and practices such as forced sterilization.

For the sake of brevity and conceptual clarity, the group decided to focus specifically on how coercion affects women's sexual and reproductive lives rather than
FOREWORD

INTRODUCTION

\section{DEFINING THE LINKS}

WHAT DO WE KNOW? THE CONTEXT OF COERCIVE SEX

- Coercion within consensual unions.

- Forced defloration

- Coercion as big business

- Sexual Coercion in Crisis Situations

DEFINING "COERCION" AND "CONSENT" CROSSCULTURALLY

2. MEN'S VIOLENCE: ORIGINS, MYTHS, AND SCIENCE

3. RESEARCH ISSUES AND METHODOLOGY

4.

RECOMMENDATIONS

\section{APPENDICES}

LIST OF

PARTICIPANTS

\section{BIBLIOGRAPHY}

\begin{tabular}{|l|}
\hline \hline Box1 \\
Impacts of Violence \\
on Women's Sexual \\
and Reproductive \\
lives \\
- STDs/HIV \\
- Unwanted pregnancy \\
- Abortion-related injury \\
- Fear of sex/loss of \\
pleasure \\
- Miscarriage and low \\
birth weight from battering \\
during pregnancy \\
- Violent sexual initiation \\
- Premature labor \\
- Gynecological problems \\
- Inability to use condoms \\
- Genital mutilation \\
- Forced abortion of \\
females foetuses
\end{tabular}


address all the intersections between violence and reproductive health. For example, while issues such as forced sterilization and battering during pregnancy are clearly important, mainstream human rights and reproductive health organizations have already given some attention, albeit inadequate, to these topics. By contrast, the issue of how sexual coercion operates in the lives of individual women and girls has received relatively little attention from family planning and reproductive health practitioners and researchers. Exploring these links was the task the group agreed to embrace.

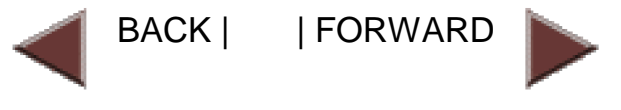




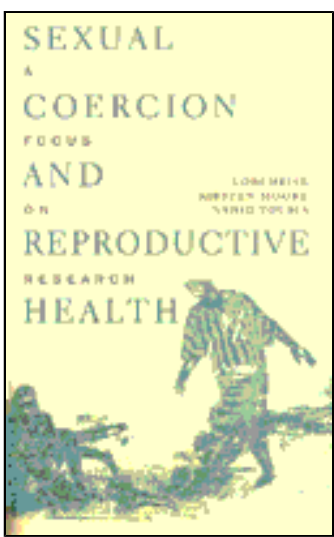

To provide a context for the discussion, Lori Heise of the Health and Development Program offered a brief overview of existing research documenting patterns of coerced sex worldwide (see Box 2) and the impact of sexual coercion on women's sexual and reproductive health.

Significantly, many of the key health outcomes of coerced sex -including unwanted pregnancy and STDs- have both direct an( indirect relationships to abuse. To illustrate her point, Heise used the case of unwanted pregnancy.

Abuse can lead directly to unwanted pregnancy either through rape or by affecting a woman's ability to negotiate contraceptive use (as in the case where a married woman is afraid to raise the issue of of contraceptive use for fear of being beaten or abandoned). Abuse can Impacts of also lead indirectly to unwanted pregnancy by increasing certain "risk Violence on behaviors" such as alcohol use, early sexual initiation and sex without Women's using contraception (see Figure 1).

\section{A certain Box 2 \\ percentage of unwanted \\ EVIDENCE OF COERCED SEX WORLDWIDE} pregnancies are clearly a direct result of forced sex. A study conducted at the Maternity Hospital Lives in Lima, Peru found that 90 percent of young mothers aged 12 to 16 were victims of rape -the majority by their father, stepfather or other male relative (Rosas, 1992). A similar study from the United States found that among 445 women who became pregnant as teenagers, 33 percent reported experiencing coerced/unwanted sexual intercourse and 23 percent became pregnant

- In the central Baganda region of Uganda, 22 percent of women said that they had been forced to ahve sex against their will at some point in their adult lives (Okongo, 1991.)

- National random surveys from Barbados, Canada, the Netherlands, New Zealand, Norway and the United States reveal that 27 to 34 percent of women interviewed have been sexually abused during childhood (Handwerker, 1993; Haskell and Randall, 1993: Draaijer, 1988: Martin et al., 1993; Schei, 1990; Lewis, 1985; Finkelhor et al., 1990).

- A study of 160 Egyptian girls and women revealed that sexual aggression by adult men toward young girls occurred in 45 percent of low socioeconomic status families and 34 percent of high SES families (deChesney, 1989).

- In India, close to 26 percent of 133 postgraduate, middle- and upper-class students interviewed reported having been sexually abused by the age of 12 (Castelino, 1992).

- In a 1992 study of 400 primary school students (average age 13.94 years) randomly selected from 40 schools in the Kabale District of Uganda, 49 percent of sexually active girls said tehy had been forced to have sexual intercourse, and 22 percent stated that they had been given gifts or rewards (Bagarukayo, et al., 1993).
FOREWORD

\section{INTRODUCTION}

\section{DEFINING THE ㄴINKS}

WHAT DO WE KNOW? THE CONTEXT OF COERCIVE SEX

- Coercion within consensual unions.

- Forced defloration

- Coercion as big business

- Sexual Coercion in Crisis Situations

DEFINING "COERCION" AND "CONSENT" CROSSCULTURALLY

2. MEN'S VIOLENCE: ORIGINS, MYTHS, AND SCIENCE

3. RESEARCH ISSUES AND METHODOLOGY

4.RECOMMENDATIONS

\section{APPENDICES}

LIST OF

\section{PARTICIPANTS}

\section{BIBLIOGRAPHY}

Research from the

United States

indicates that rape

results in STD

transmission in 4 to

30 percent of victims

(Koss and Heslet,

1992). Untreated

STDs can lead to

pelvic inflammatory

disease and

eventually to

infertility, an

especially dire

consequence in

societies where

women's worth

derives largely from

her ability to bear

children. 
by the perpetrator

(Gershenson et al., 1989). The fathers of these children

were predominantly boyfriends or friends of the teen mother, rather than family members or strangers.

Victimization may also lead indirectly to unwanted pregnancy through the unresolved feelings and behavior patterns that past abuse creates. Two of the most commonly documented consequences of sexual abuse are early onset of sexual activity and an inability to distinguish sexual from affectionate behavior (Donaldson, Whalen and Anastas, 1989; Browne and Finkelhor, 1986; Riggs, Alario and McHorney, 1990). Frequently, the shame and stigma that abuse survivors experience leave them feeling vulnerable, unloved and unable to say "no" to things they do not want to do, such as having sex or using drugs. Moreover, as "damaged goods," they do not feel worthy or capable of undertaking self-protective behavior, such as contraception.

A recent study of adolescent mothers in the U.S. state of Washington found that young women who had been sexually abused during childhood began intercourse on average a year earlier than nonvictimized mothers. They were also more likely to use drugs and alcohol and less likely to practice contraception. Only 28 percent of the victimized teens used birth control at first intercourse, compared to 49 percent of their nonvictimized peers (Boyer and Fine, 1992). Another U.S. study confirmed that women survivors of childhood sexual abuse are nearly three times more likely than nonvictimized youth to become pregnant before the age of 18 (Zierler et al., 1991).

Similar multiple pathways are evident in the relationship between sexual abuse and STDs. Obviously, a woman or girl may contract an STD directly as a result of sexual abuse or rape. But sexual victimization in childhood or adolescence can also increase an individual's chance of contracting STD or HIV in adulthood by affecting their future sexual behavior.

This relationship emerges clearly in the research of seminar participant Penn Handwerker, an anthropologist who has conducted extensive field work on sexual behavior in the English-speaking Caribbean. In his study of 407 randomly selected men and women on the island of Barbados, for example, Handwerker found that sexual abuse in childhood emerged as the single most important determinant of high-risk sexual activity during adolescence for both women and men (1993). After controlling for a 
wide range of socioeconomic and home-environment variables (such as absent father), sexual abuse remained strongly linked to both the number of partners adolescents have and to their age at first intercourse. For men, physical, emotional and/or sexual abuse in childhood also highly correlated with lack of condom use in adulthood, after controlling for many other variables.

In addition to these complex and overlapping pathways, sexual and physical abuse appear to be connected to some common gynecological problems, including vaginal discharge and chronic pelvic pain. A study conducted in Norway by conference participant Berit Schei, for example, found that women living with a physically and/or sexually abusive partner reported significantly more gynecological symptoms and sexual problems than women living in violence-free relationships (Schei and Bakketeig, 1989). Several additional studies link physical and sexual abuse and chronic pelvic pain (Walker et al., 1992; Schei 1990; Wood et al. 1990; Reiter et al., 1991).1

Schei's research even suggests that traumatic events may have a cumulative effect on women, with each experience increasing the likelihood of developing chronic pelvic pain or other somatized symptoms. In a related study, Schei (1990) also demonstrated a strong association between living in a physically abusive relationship and one or more episodes of a medically treated PID. When women's sexual histories (such as multiple sexual partners, early first intercourse) and use of an IUD are statistically controlled for, the relationship weakens slightly but still remains highly significant. Clearly, these associations deserve further study.

A study by Susanna Rance entitled "Control and Resistance: Empowering Strategies in the Reproductive Lives of La Paz Market Women" (1994) captures many of the indirect but nonetheless pernicious impacts of coercion on women's reproductive health. Based on interviews with 30 Bolivian women of Aymara origin, the study documents the intricate ways that coercion and male dominance operate to limit and shape women's sexual and reproductive lives (see Appendix 1). The women interviewed often found it difficult to refuse sex, and faced accusations of indifference or infidelity if they tried to do so. Rape in marriage was common, though rarely identified as such, since wives were often expected to service their husbands sexually.

Rance's study also explores the complex relationship between male control and contraceptive decisionmaking. "In many of the interviews," notes Rance, "it is clear that the woman's ability to control her fertility depends on her ability to control her man, or to evade his attempts to control her" (Choque, Schuler and Rance, 1994:11). Many women are afraid to bring up the issue of contraceptive use for fear of being beaten, abandoned or accused of infidelity-a concern documented in studies from Mexico, Peru and Kenya as well (Folch-Lyon et al., 1981; Fort, 1989; Banwell, 1990). Others opt for less reliable forms of contraception such as periodic abstinence to avoid sexual relations that they find painful or unpleasant. Still others who wish to use natural family planning cannot do so because their husbands will not respect their fertile days. Attempts to avoid intercourse often lead to verbal and physical abuse. As one woman observed, "no" is not an 
option,

1. Laparoscopy examinations suggest that chronic pelvic pain is more closely associated with psychiatric findings than with organic pathology Harrop-Griffiths, et al., 1988). Psychologists conceptualize the pain among victims as a defense against the overwhelming emotions connected to the traumatic experience.

\section{BACK | | FORWARD}




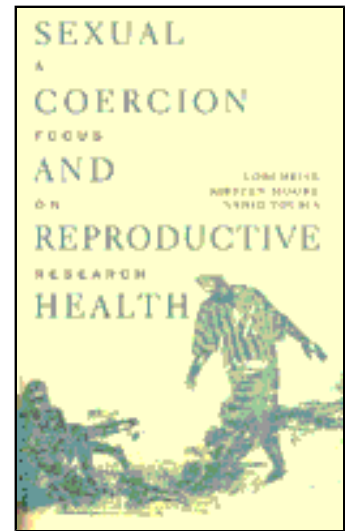

When most people think of sexual violence, the first image that comes to mind is a violent rape, perpetrated by a stranger in a dark alley. In reality, this type of anonymous event is rare among instances of sexual coercion. Most coerced sex takes place among individuals known to each other: family members, courtship partners, acquaintances or spouses. A substantial subset of coerced sex also takes place against children or adolescents, the vast majority of whom are girls. This tendency toward young victims appears to hold true in both industrialized and nonindustrial ized countries. Justice system statistics and data from rape crisis centers in Chile, Peru, Malaysia, Mexico, Panama, Papua New Guinea and the United States, for example, indicate that between oneand two-thirds of the sexual assault victims are 15 years and younger (Heise, Pitanguy and Germain, 1994).

Sexual coercion can take place throughout a woman's life cycle. Children as young as several months old have been known to be raped or sexually molested. During childhood, young girls become easy targets for older male relatives or friends who can take advantage of their greater power and children's trusting nature to exact sexual favors through force or deception. As they mature, young girls begin to attract even more sexual attention; frequently boyfriends, teachers, or other men in authority force them into sexual encounters they do not want. Some are forced to marry men whom they scarcely know and are expected to be sexually available to them at all times. All too often, sex in marriages is not a mutually pleasurable event but a brutal service exacted by force, threat or social convention. Even in old age, women are not immune: rape crisis centers report victims in their seventies and older.

The great variety of sexually coercive situations that women face was made painfully apparent during the morning's first panel, entitled "Contexts of Coercive Sex." Participants heard disturbing accounts of the various ways that women in different parts of the world have experienced forced sex. The case studies included a report by Annie George, an Indian researcher, on rape within marriage among slum dwellers in Bombay; a description by Algerian gynecologist Dr. Malika Ben Baraka of the consequences of forced defloration among young brides in Algeria; a presentation by human rights activist Therese Caouette on the forced prostitution of young women in Thailand; and a discussion by Dorothy Thomas of Human Rights Watch on sexual coercion during conflict and war situations.

\section{Coercion within Consensual Unions}

The panel began with a report by Annie George, a researcher from the Tata Institute of Social Science in India, on her research on sexual ity among 35 low-income
FOREWORD

INTRODUCTION

\section{DEFINING THE LINKS}

WHAT DO WE KNOW?

THE CONTEXT OF COERCIVE SEX

- Coercion within consensual unions.

- Forced defloration

- Coercion as big business

- Sexual Coercion in Crisis Situations

DEFINING "COERCION" AND "CONSENT" CROSSCULTURALLY

2. MEN'S VIOLENCE: ORIGINS, MYTHS, AND SCIENCE

3. RESEARCH ISSUES AND METHODOLOGY

\section{RECOMMENDATIONS}

\section{APPENDICES}

LIST OF

PARTICIPANTS

BIBLIOGRAPHY

Sometimes, he would want to do it, even though I didn't feel like it. I would tell him sometimes that I did not want it, and that he came to see me only to have sex. Then he would get very angry and beat me and say that I did not like him because I was having an affair. It was easier to just close my eyes and give in. 
women in Bombay. Undertaken as part of a 13-country research project on Women and HIV sponsored by the International Center for Research on Women (ICRW), George's study documented an alarming amount of coerced sex taking place within marriage. Although the main purpose of the study was to explore how women understand their own sexuality, the study also revealed a profound pattern of physical, emotional and sexual abuse by intimate male partners. Sixteen of the thirty-five women experienced regular beatings and sexual violence and all the women reported at least one significant instance of abuse.

As with other matters pertaining to their bodies, most of the women in the study were largely ignorant about sexual relations between men and women until they learned of it on their wedding nights. "It was our misconception that women living in slums would know more about sex as a result of their lack of privacy. But most women described their first sexual encounter as rape, and subsequent sexual encounters as traumatic, unwanted and forced. Men assumed that through marriage they would have sexual access to their wives whenever and however they wanted."

Usually a female relative of the groom would have to "trick" the wives into sleeping with her husband the first time. As one respondent described:
My sister-in-law got me into a room on some pretext. Then my husband came and locked the door of the room. He tried to touch me and his hands and legs were all over me. I started screaming until he went away.

Finally when he did it the first time, it was very painful. I cried for days. I was scared, wondering what he was doing to me. I felt violated. I would tell my mother-in-law that I wished the night would never come because at night her son used to come inside to sleep ... she used to laugh at this....

George noted that the trauma of sexual initiation for these women was generally exacerbated by the man's own lack of sexual knowledge and the woman's young age.

George also chronicled the many ways women tried to resist unwanted sex, from feigning menstruation to physically resisting unwanted advances. As George points out, women frequently acquiesce to sex in order to avoid what they perceived as a more threatening outcome, such as being beaten or abandoned. "There is a limit to even the supposedly patient (samajdar) man," notes George. "Then, the man forces sex on his wife if she does not agree. Or else the woman, to preserve her dignity, or family honor, or to maintain peace, gives in to the man's desires."

This raises an interesting question about the nature of "consent" Linder such circumstances. George questions whether the notion of consent by virtue of marriage has any validity in the Indian context where women are married off at an early age, have no say in whom they will marry and are given virtually no information about sex prior to their wedding night. "The centrality of marriage within the Indian cultural context is so dominant," she notes, "that women have no choice but to be married." 
Malika Ben Baraka, a physician from Algeria, also spoke poignantl about the trauma of sexual initiation in her country:

\begin{abstract}
Imagine it is 3:00 a.m. on a Friday morning and the emergency room of an urban hospital is filled with an angry mob. There is a policeman trying to calm them down and a very pale 17year-old girl. But the staff move quickly, as they are used to this scene.
\end{abstract}

Thursday, Baraka explains, is the traditional day for marriage celebrations. The people yelling are neighbors. The man with the loudest voice is the bride's father. He tells the doctor "This is my daughter's wedding night and those people are pretending that my daughter is not a virgin. I want you to examine her and clear my honor. I swear if she is not a virgin, I will kill her right now."

In another version of the story, a young woman is rushed to the emergency room on her wedding night, hemorrhaging profusely. An ob/gyn exam reveals scratches and cuts on her labia minora and a deep cut of 2-3 centimeters in her vagina. Her defloration was so abrupt that she will suffer in each subsequent sexual act.

These are results of the official celebrations of a young woman's defloration in Algeria. As Ben Baraka explains, an Algerian girl's entire education is geared toward respecting male authority and safeguarding her virginity until marriage. Loss of virginity brings permanent dishonor to herself and her family. The only way to cleanse the family honor, once tarnished, is to kill the woman, a task normally undertaken by her own father, brother or uncle.

A girl's family lives in daily fear that she will lose her virginity before marriage; that is why she is married early, and often without her consent. Twenty-year-old girls are frequently married to 50-year-old men as second, third or fourth-order wives. On her wedding day, the young bride is escorted to her new spouse's house and conducted directly to the nuptial bed. A party takes place outside of home.

Defloration must be as quick and as bloody as possible with immediate evidence of defloration: a sheet or her dress is shown like a flag to those in the party. This is saluted by gunshot and the dancing accelerates.

According to Ben Baraka, defloration is an urban as well as rural phenomenon although in urban areas, the public celebration is more discreet. Within the modern classes, there is no formal verification of defloration; it is assumed that an educated Algerian man accepts to marry only a virgin. With the resurgence of Muslim fundamentalism, however, virginity has again risen in importance and families are now requiring a "virginity" certificate before marriage.

\title{
Coercion as big business
}

The panel's third speaker, Therese Caouette of Asia Watch, reminded participants that "coercion" can also take a highly organized and, lucrative form: forced prostitution. 
documenting the treatment of young Burmese women trafficked into Thailand for the purpose of prostitution. A recent Asia Watch report conservatively estimates that between 20,000 and 30,000 Burmese women and girls are enslaved in Thai brothels, with about 10,000 new recruits trafficked across the border each year (Asia Watch, 1993).

The situation of Burmese women in Thailand illustrates all of the common dimensions of trafficking in women. Capitalizing on the violent repression of the Burmese government and deepening poverty in the countryside, agents acting on behalf of the Thai brothel owners infiltrate ever more remote areas of Burma looking for unsuspecting recruits. The agents promise the women and girls jobs as waitresses or dishwashers, with good pay and new clothes. Family members of friends typically accompany the woman to the Thai border, where they are given "an advance on the girl's salary" ranging from $\$ 400$

from someone associated with the brothel. As Caouette points out: "This payment becomes the debt, usually doubled with interest, that the women and girls must work to pay off, not by waitressing or dishwashing, but through sexual servitude."

Once confined in the Thai brothels, escape is virtually impossible. Brothel owners use every available means of violence and intimidation to keep the women isolated and compliant. Women have to work 10 to 18 hours a day and service five to fifteen clients. Anyone attempting to leave the brothel faces physical punishment, threats of reprisal against her family for "defaulting" on her debt, and arrest by the police for being an illegal immigrant. Far from being a potential source of protection, the Thai police are frequently clients of these illegal establishments and many are intimately involved in the trade.

\section{Sexual Coercion in Crisis situations}

The final panelist, Dorothy Thomas, described a different but related context for sexual coercion: refugee and conflict situations. As the director of the Women's Rights Project at Human Rights Watch, Thomas and her staff have documented the many ways that war and dislocation increase women's vulnerability to sexual violence and exploitation.

According to Thomas, rape is often used as a tactical device to accomplish discrete political ends: to intimidate and punish individual women, to destabilize and demoralize communities, and to drive unwanted populations from their land. In Burma, for example, rape was part of an orchestrated campaign by the Burmese government to drive the Rohingya, a Muslim minority group, out of the country and into Bangladesh. Government soldiers in Peru have likewise used rape to exact information, punish "Communist sympathizers" and to demonstrate the soldiers' domination over civilians. Wherever it is used, soldiers rape to subjugate and inflict shame upon their victims, and by extension, their victims' families and communities.

Thomas discussed the wide range of reproductive health issues this type of gendered persecution raises, including STDs, unwanted pregnancy, genital trauma and profound depression. 
The trauma of rape is frequently compounded by an almost complete lack of reproductive health services in refugee settings-a reality that the international community is just now beginning to address. Thomas emphasized that rape by soldiers is just one of the indignities these women often face: wartime desperation often forces women into "trading" sex for permission to cross borders or to secure food for their children.

The morning panel made it painfully clear that sexual coercion extends far beyond the stereotypical image of the lone, anonymous rapist. Sexual coercion and exploitation can be incredibly cold and calculating, as in the case of organized trafficking, or it can be excruciatingly intimate, as in the case of marital rape. Its perpetrators can be strangers, friends, lovers, family members or agents of the state. Many participants noted they had failed to recognize the full spectrum of sexual coercion prior to the panel.

Nonetheless, it is important to recall the positive and joyous aspects of sex as well. As Sajeda Amin of Bangladesh emphasized, to focus only on the negative is to paint an unnecessarily grim image of the female sexual experience. 


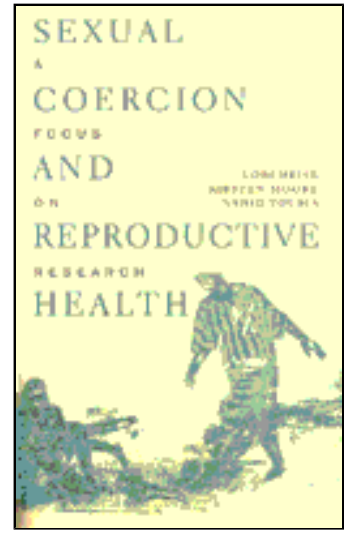

Any effort to investigate sexual coercion in different cultural contexts requires confronting the difficult issue of how to define "consent" for the purposes of research. Some individuals argue, for example, that there is no such thing as "marital rape" in their culture; marriage by definition grants men unrestricted sexual access to their wives. Others would argue that women have a right to refuse unwanted sex regardless of what male-defined norms of marriage and "culture" might say.

Indeed, all societies have forms of sexual violence that are socially proscribed and others that are tolerated, or in fact encouraged, by social custom and norms. Most societies condemn sex between adults and children and forced sexual intercourse with an unmarried virgin. Many, however, openly or tacitly accept forced sex within marriage or against women who are sexually experienced or perceived as provocative. Amazingly absent from most cultural definitions of abuse are the volition, perceptions and feelings of the woman or girl. Often the context of an act (who did it to whom and under what circumstances) is more important in defining its "moral acceptability" than the act itself or its impact on the woman (see Box 3).

One way to conceptualize coercive sex is along a violence continuum from transgressive to tolerated coercive sex (see Figure 2). At one end would be those acts that are clearly perceived as wrong by those in power and are swiftly punished; at the other would be those acts that are tolerated or condoned, regardless of how

\section{Box 3}

Transgressive or Tolerated Rape?

Transgressive or Nonnormative Rape is defined as "the illicit, uncondoned genital contact that is both against the will of the woman and in violation of social norms for expected bahavior (Rosee, 1993). This definition depicts the stereotypical rape that consists of a surprise attack on a virtuous woman. In fact, the wrongness of rape is often determined not by the nature of the act comitted but by the marital or moral status of the woman.

Tolerated or normative rape is defined as "genital contact that the female does not choose, but that is supported by social norms." Coercive sex is supported by socia norms when "there is no punishment of the male or the female only is punished; if the reape itself is condoned as a punishment of the female; if the genital contact is embedded
FOREWORD

INTRODUCTION

\section{DEFINING THE} LINKS

WHAT DO WE KNOW?

THE CONTEXT OF COERCIVE SEX

- Coercion within consensual unions.

- Forced defloration

- Coercion as big business

- Sexual Coercion in Crisis Situations

DEFINING "COERCION" AND "CONSENT" CROSSCULTURALLY

2. MEN'S VIOLENCE: ORIGINS, MYTHS, AND SCIENCE

3. RESEARCH ISSUES AND METHODOLOGY

\section{RECOMMENDATIONS}

\section{APPENDICES}

\section{LIST OF \\ PARTICIPANTS}

BIBLIOGRAPHY 
the woman

experiences the

event. Generally,

whether sexual

coercion is seen as

normative or

"transgressive"

depends on whether

a woman is sexually

chaste, who she

"belongs to" (is she

married, still living at

home,

independent), who

the perpetrator is

(does he have

sanctioned sexual

access to the woman) and the nature of the sexual act

(penetrative versus nonpenctrative).

Within any one society there may be contested areas where the lines are in transition. In the United States, for example, the line between acceptable and nonacceptable levels of coercion among dating partners is clearly changing. Acts that would have been cited as the girl's fault or ascribed to "bad manners" on the part of the boy 20 years ago are increasingly being labeled "date rape." The social definition of acceptable behavior is culturally defined and therefore subject to change. The dominant definition that holds sway at any one time, however, has nothing to do with whether coercion actually occurred. This is a subjective reality that can only be determined by the woman.

Patricia Rozec, a psychologist who studies sex and violence crossculturally, suggests that female choice should be the benchmark for definitions of rape. She prefers the concept of choice to "consent" because it does not implicitly assume that men initiate all sexual overtures. Rozee rejects the tendency in anthropology to accept maledefined social norms rather than women's experience when defining rape cross-culturally. "It is not uncommon," she notes, "to find reports of an exceedingly violent male practice that an ethnographer is reluctant to label as rape simply because it is socially condoned.... While it is important to accurately and respectfully record life in other cultures,-it is also important not to embrace androcentrism in order to avoid ethnocentrism" (Rozee, 1993:499-514).

In general, conference participants endorsed the idea of a universal standard for identifying coerced sex across cultures. Sensitivity to culture is important when designing strategies to change cultural beliefs and attitudes: education programs must start where people are and help them come to adopt more progressive beliefs. But respect for culture should not be allowed to compromise the ultimate goal: voluntary, safe sexuality for all people. ${ }^{2}$

In an article on domestic violence in Ghana, Ghanaian lawyer Ofeibea-Ofboagye argues that "a culture that teaches male mastery and domination over women must be altered" :
Empowering women to make decisions about sex, about partners, about childbearing is a goal shared by many. The local means to reach this goal may be different-this may be influenced by culture. But just because there are no culturally recognized definitions of violence or sexual coercion doesn't mean that it doesn't exist.

-GITA MISRA 
to and subtract from the fabric of our society in order to create a masterpiece. I think we can accomplish this by undoing some of the cultural norms and replacing them with others, different but equally strong and beautiful (Ofeibea-

Ofboagye, 1994).

This approach is consistent with the rapidly expanding women's human rights movement, which seeks to preserve the positive elements of all cultures but to dismantle those cultural beliefs and practices that harm women and deny their right to bodily integrity. Women at the forefront of this movement point out that culture is always changing; appeals to culture are often merely an excuse to justify practices oppressive to women. As Nahid Toubia observes, "Why is it only when women want to bring about change for their own benefit that culture and custom become sacred and unchangeable?"

The group also grappled with appropriateness of calling certain encounters "rape" or coerced sex when a woman herself would not use this term. The group felt that research definitions should be based on behavioral definitions of what actually occurred rather than on whether a woman acknowledges the event as "rape" or not. Women frequently internalize their culture's mythology about rape and may not feel that their experience, while painful, "qualifies" as rape. As Nahid Toubia observes, "Just because a woman doesn't call it rape doesn't mean she doesn't feel violated. She may not have the language, or she may never have been asked."

The truth in this statement becomes clear when one listens to the words of women who are "refraining" their experiences of coercive sex in light of new information. Consider the following quote from a Latin American woman being interviewed about her sexual life:
My sex life in marriage has been dominated by rape, rape, rape -and nothing to do with love. I didn't know that what I experienced was rape. I first found out about that when I went into therapy -that what I described was nothing other than rape. I thought that rape was something that happened in a dark, remote street in the middle of the night. I didn't know that it could also happen in a marriage bed. (Agger, 1994:104).

A similar "reframing" is evident in the sexual initiation stories of exiled Iranian women living in the United States. When interviewed by anthropologist Mary Hegland about their wedding nights in Iran, most described the experience as violent and highly traumatic (Hegland unpublished). Many gave graphic details of being held down by relatives while the man forced himself on her. While the women said the term "rape" would never be applied to this experience in Iran, they freely used terms like "rape" and "torture" to describe the experience, after being exposed to this language in the United States. This new language merely gave voice to feelings they already had. 


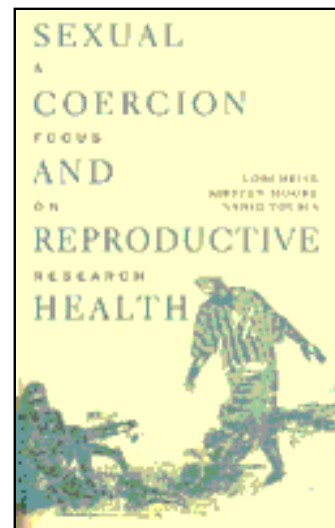

Today we all know that most acts of violence are committed by men. This knowledge is so much a part of our mental landscape that we take it for granted. But the time has come to focus our attention on it so that we can begin to explore ways of significantly reducing the incidence of violence

-Myriam Medzian
FOREWORD

INTRODUCTION

1. DEFINING THE

LINKS

\section{MEN'S VIOLENCE:}

ORIGINS, MYTHS, AND SCIENCE

BOYS WILL BE BOYS

THE IMPORTANCE OF BEING

MALE

GENDER STEREOTYPES AND

SEXUAL COERCION

3. RESEARCH ISSUES AND METHODOLOGY

pursuit has only recently received critical attention. Even classic Western works such as On Aggression by Konrad Lorenz fail to recognize that it is largely male aggression that is the problem. Nonetheless, cross-cultural data confirm that almost everywhere, violence -whether in the form of rape, property crimes or playground bullying -is a predominantly male endeavor (Archer and Lloyd, 1985). In a survey of crime in 31 countries, for example, men accounted for about 87 percent of all arrests and 90 percent of arrests for homicide between 1962 and 1980 (Simon and Baxter, 1989).

\section{RECOMMENDATIONS}

\section{APPENDICES}

LIST OF

PARTICIPANTS

BIBLIOGRAPHY

This simple but compelling fact raises several equally provocative questions. If men commit the majority of violent acts, does this mean that men are inherently more violent than women? Does men's penchant for violence result from biology, social conditioning or a combination of both? And perhaps of most interest, if men's propensity for violence has a biological component, does this mean it is somehow "natural" and therefore impossible to change?

These and other questions were the basis of the seminar's second major panel featuring Myriam Miedzian, philosopher and author of Boys Will be Boys: Breaking the Link Between Masculinity and Violence; Dr. Peggy Sanday, anthropologist and expert on rape cross culturally; and Steve Brown, a clinical psychologist and sex educator who works with delinquent youth on issues of sexual coercion.

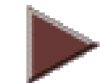




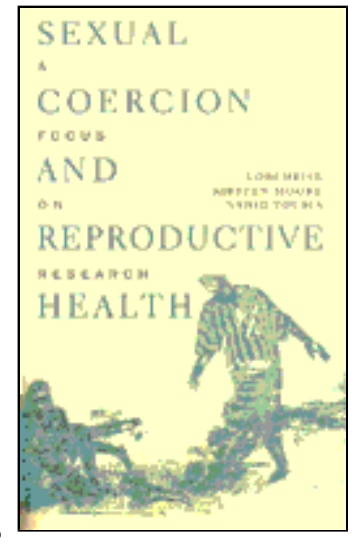

The idea that violence and dominance are somehow inherent to men's nature is an idea with many adherents in different parts of the world. It has been used to justify war, men's dominance of the public sphere, and all manner of atrocities committed against women, nature and other human beings. Especially in the realm of sexuality, the belief persists in many quarters that male sexuality is inherently predatory: men need frequent sex (so the theory goes), preferably with multiple partners, whereas women are essentially passive. Ironically, in many cultures, the belief in female passivity coexists with an equally widespread belief that female sexuality is powerful and must be monitored and controlled at all times.

Popular culture, religious dogma, and scientific discourse perpetuate the idea of an insatiable male "sex drive." Frequently, this idea is used to justify sexual pursuit regardless of a woman's will. Men are portrayed as captive to their libido and therefore not fully responsible for their actions. Sometimes men's raging hormones are portrayed as the culprit, whereas at other times, male behavior is couched in the language of evolutionary biology in which male promiscuity is seen as a vestige of evolutionary forces that confer "selective advantage" on men who impregnate as many women as possible.

Regardless of the rationale, the social acceptance of men's violence runs deep. The belief in the "naturalness" of men's aggression is a core one that we must challenge in order to build a global consensus against gender-based abuse.

Although theory building in the field of violence is still very much in flux, there is a growing consensus among experts that violence is neither an entirely biological phenomenon nor solely a product of culture. As Myriam Miedzian argued during her presentation on the origins of male violence:

We must begin to move beyond a simplistic view of violence in which one side contends that it is biological and therefore nothing can be done about it, while the other side asserts that human beings are naturally good and violence is caused by socialization alone.

In her presentation, Miedzian argued that although there appears to be some biological basis for men's greater propensity toward violence, this potential can be either reinforced or largely eliminated, depending on socialization.
FOREWORD

INTRODUCTION

1. DEFINING THE LINKS

2. MEN'S VIOLENCE: ORIGINS, MYTHS, AND SCIENCE

BOYS WILL BE BOYS THE IMPORTANCE OF BEING MALE

GENDER STEREOTYPES AND SEXUAL COERCION

3. RESEARCH ISSUES AND METHODOLOGY

4.RECOMMENDATIONS

\section{APPENDICES}

LIST OF

PARTICIPANTS

\section{BIBLIOGRAPHY}

To say that men as a
group are more violent
than women is by no
means to assert that all
men are violent,
violence - prone or
accepting of violence
as a way of resolving
conflicts and attaining
power. It means only
that a significantly
higher percentage of
men than women
exhibit these
tendancies.
-MYRIAM MEDZIAN

To say that men as a group are more violent means to assert that all men are violent violence - prone or conflicts and attaining power. It means only men than women exhibit these

-MYRIAM MEDZIAN
As Miedzian points out, acknowledging that humans have a biological potential for violence-even that men as a class may be at higher risk for committing violent acts than women-does not mean that violence is entirely genetic and immutable. "If human beings were not biologically capable 
of violence, violence would not exist, just as a child cannot fly simply because he wants to play Superman.

Nor does a biological component to violence mean that it must be acted upon. To make her point, Miedzian cites the ability of even a young child to control the biological (and often powerful) urge to urinate or defecate in inappropriate situations. "If a child can learn not to pee in public, it is reasonable to expect that a child can master whatever biological propensity he may have toward easy frustration or anger.

Indeed, Miedzian believes whatever biological basis may exist for men's greater propensity toward violence probably stems from a lower threshold for frustration, greater irritability and impulsiveness and a tendency toward rough and tumble play during childhood (the latter tends to encourage the expression of anger or frustration through physical activity rather than verbal reaction, see Box 4). Although a factor, these biological tendencies play only a small role in accounting for men's greater proclivity toward violence. Far more important, Miedzian argues, are the powerful social factors -male socialization, peer pressure, the media, and the military-that virtually breed violent behavior in men.

In fact, Miedzian lays a large share of the blame for the epidemic of male violence in her own U.S. culture on a "masculine mystique" that encourages toughness, dominance and extreme competitiveness at the expense of honest emotion, empathy and communication. Whereas aggressive impulses in girls are generally discouraged and censored by authority figures, boys are taught they must be tough if they want to be "a man." Strict codes of conduct are enforced through peer pressure not to be "a sissy," "a fag" or a "wus." Television, films, video games and combat sports further reinforce rigid gender roles and violent behavior.

During her panel presentation, anthropologist Peggy Sanday also provided information suggesting that men's violence is Dot inevitable. Dr. Sanday presented findings from her now-classic comparative study of rape in 156 tribal societies. According to her detailed analysis of the ethnographic record, rape of women by men was totally absent or extremely rare in 47 percent of the cultures she studied (Sanday, 1981). Even if one cedes that some of the societies designated "rape free" probably represent inadequacies in the ethnographic record rather than truly nonviolent societies, the number of examples cited (and the descriptions of life in these societies) suggests that there have been at least some cultures not plagued by sexual violence (especially since the study eliminates any societies in which insufficient information exists to determine the presence or absence of rape).

Two other studies of wife abuse cross-culturally (Levinson, 1989, Counts, Brown and Campbell, 1992) unearth additional examples of cultures in which gender-based violence is absent or exceedingly rare. In his ethnographic review of 90 peasant and small-scale societies, for example, Levinson (1989) identified 16 that could be described as "essentially free or untroubled by family violence." The existence of such cultures - even if few in number - stands as proof that violence against women is not an inevitable outgrowth of male biology, sexuality, or 
hormones. Apparently it is "male conditioning," not the

"condition of being male" that appears to be the problem.

$<$ BACK | | FORWARD 


\section{Chapter 2}

\section{The importance of being male}

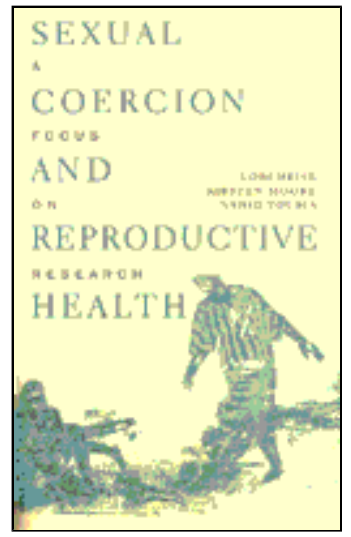

Although what it means to be "male" varies among different cultures and within different segments of the same culture, the importance of the masculine mystique appears to be a common element in many, but not all, societies. In his book Manhood in the Making: Cultural Concepts of Masculinity, anthropologist David Gilmore (1990) notes that across many cultures "there is a constantly recurring notion that real manhood is different from simple anatomical maleness, that it is not a neutral condition that comes about spontaneously through biological maturation but rather is a precarious or artificial state that boys must win against powerful odds" (p. 11).

Men in many cultures strive daily to prove to themselves and others that they qualify for inclusion in the esteemed category of "male." The fear accompanying this insecurity derives in part from a gendered system that assigns power and status to that which is male and denigrates or subordinates that which is female. To be "not male," is to be reduced to the status of woman, or, worse, to be "gay".

A growing number of theorists have begun to argue that violence against women is partly fueled by men's fundamental insecurity over their masculinity (Lancaster, 1992; Stoltenberg, 1989; Segal, 1990). To say that men are insecure does not in anyway condone their coercive conduct, but it can help us understand the phenomenon and suggest avenues for intervention.

One way to feel unambiguously male in many cultures is to dominate women, to behave aggressively and to take risks. A "real man" in the Balkans, for example, is one who drinks heavily, fights bravely and shows "Indomitable virility" by fathering many children (Denich, 1974). In eastern Morocco, "true men" are distinguished by their physical prowess and heroic acts of both feuding and sexual potency (Marcus, 1987). On the South Pacific island of Truk, fighting, drinking, defying the sea and sexually conquering women are the true measures of manhood (Caughey, 1970; Marshall, 1979; Gilmore, 1990).

Significantly, sexual conquest and potency appear as repeated themes in many cultural definitions of manhood, placing women at increased risk of coercive sex. This is as true in the United States as it is elsewhere. Recently, nine teenage boys from an upper-middle-class suburb of Los Angeles were arrested for allegedly molesting and raping a number of girls, some as young as ten. The boys, members of a group called the Spur Posse, acknowledge having sex with scores of underage girls as part of a sexual competition. In tabulating their sexual exploits, the boys made reference to the uniform number of the sports stars
FOREWORD

INTRODUCTION

1. DEFINING THE LINKS

\section{MEN'S VIOLENCE:} ORIGINS, MYTHS, AND SCIENCE

BOYS WILL BE BOYS THE IMPORTANCE OF BEING MALE

GENDER STEREOTYPES AND SEXUAL COERCION

\section{RESEARCH ISSUES AND METHODOLOGY}

\section{RECOMMENDATIONS}

\section{APPENDICES}

LIST OF

PARTICIPANTS

\section{BIBLIOGRAPHY}

When masculinity is
associated with
aggression and sexual
conquest, domineering
sexual behavior and
violence become not
only a means of
structuring power
relations between men
and women, but also a
way of jockeying for
power and position
among men.
-IRMA SAUCEDO

When masculinity is associated with conquest, domineering sexual behavior and violence become not and women, but also a 
who are their heroes: "I'm 44 now-Reggie Jackson. I'm 50David Robinson." Tellingly, some of the boys' fathers appeared boastful of their sons' conquests. In a New York Times article about the rapes, one father praised his son as "all man" and insisted the girls his son had sex with were "giving it away" (Gross, 1993).

When masculine ideals are associated with violence, virility and power, one can easily see how male sexual behavior might emerge as coercive and aggressive. 


\section{Chapter 2}

\section{Gender Stereotypes and Sexual Coercion}

During the panel's third presentation, Steve Brown, a clinical psychologist and sex educator who works with troubled youth in the United States, helped participants understand how stereotypes about "appropriate" male and female sexual behavior operate at the individual level to fuel sexual coercion among U.S. adolescents.

Brown introduced a multilevel ecological framework to help explain the many interrelated factors that contribute to sexual coercion by adolescent boys (see Figure 3). Brown's model organizes psychological and social forces into four levels of analysis, each level embedded in and interacting with those surrounding it. The innermost level of the framework examines the factors in a young person's personal history - such as prior sexual abuse - that might contribute to his or her involvement in a sexually coercive situation. The second layer, the microsystem, refers to the forces operating in the immediate context in which the sexual coercion takes place - such as the presence of alcohol or drugs. The third level is the exosystem and refers to the formal and informal social structures such as peer pressure - that impinge on the individual and his or her circumstance. Finally, the macrosystem refers to the larger cultural values, beliefs and power structures that foster sexual coercion through their strong influence over the forces that operate on the inner three levels.

To illustrate his model, Brown took the case of sexual coercion among dating partners ("date rape"), a common and growing problem in the United States. Despite the increasing flexibility of gender roles in U.S. society, traditional stereotypes - operating at the level of the macrosystem - still strongly shape the attitudes and behaviors of U.S. men and women, and are often especially rigid among boys and girls. "It is these stereotypes that set the stage on which sexual coercion gets played out," Brown argues. Starting at a very young age boys get the message that males are expected to be strong, brave, self-reliant, all - knowing, emotionless, aggressive and competitive. Also very early on boys begin to get the message that there are severe consequences for breaking the code of conduct. Boys who act in any way "unmanly" run the risk of being labeled gay and resoundingly rejected by their peers.
FOREWORD

INTRODUCTION

1. DEFINING THE LINKS

2. MEN'S VIOLENCE: ORIGINS, MYTHS, AND SCIENCE

BOYS WILL BE BOYS THE IMPORTANCE OF BEING MALE

GENDER STEREOTYPES AND SEXUAL COERCION

3. RESEARCH ISSUES AND METHODOLOGY

4.RECOMMENDATIONS

\section{APPENDICES}

LIST OF

PARTICIPANTS

\section{BIBLIOGRAPHY}

We need to impress upon bys that rape is not just bad sex, it can be excruciatingly painful and have devestating long - term effects on the girls.

-STEVE BROWN

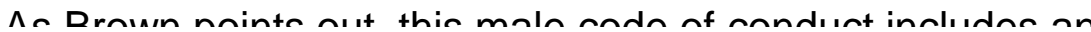



that are religiously ascribed to, especially by the troubled teens with whom he routinely works. Among the common attitudes of boys are:

- It's unacceptable for a male to be a virgin. Boys earn their manhood via sexual conquest.

- Boys don't talk about sex, they just do it.

- Boys are supposed to be sexual initiators. 'Girls like guys who take control when it comes to sex. Girls want sex as much as boys, but they have to say."no" to maintain their reputation. Therefore, when a girl says "no," she really means "maybe" or "yes." Girls want to be persuaded and are expected to struggle a little bit. Even tears are a part of the act.

- If a guy is persistent and persuasive, the girl will eventually fall into his arms and be glad she did.

- Intercourse isthe only real sex.

- Even if a girl doesn't want to have sex, it's still sex and can't really feel that bad.

- The penis has a mind of it's own. Once aroused, it can't be controlled.

These attitudes are woven into the U.S. cultural fabric: in its advertising, books, movies, television - and many are implied if not explicitly stated in religious doctrine. To some extent these ideas are part of the socialization of all American males. But high-risk teens, most of whom have other negative forces impinging on their lives often interpret and act upon these stereotypical ideal as fact.

At the exosystem level, Brown explains, comes the powerful influence of peer pressure and culture. Unfortunately for many boys, the direct benefits of peer approval often far outweigh the hypothetical risk of getting accused of rape. Likewise the benefits for girls of having a boyfriend and being popular with their friends outweigh the risk of putting themselves in situations where date rape is possible. "It's discouraging to see just how pervasive traditional sex role attitudes and behaviors are with the adolescent girls I work with," notes Brown, "despite all the progress of the women's movement in this country. Teenage girls want so badly to be liked that they are willing to put up with tremendous abuse."

At the personal level Brown cites such factors as a history of sexual or physical abuse, the absence of positive male role models and an almost complete lack of information or positive socialization about sexuality or healthy male/female relationships. As Brown points out, without realistic modeling of what it means to be male, the boys are left only the exaggerated models of maleness and sexuality provided by society at large and their male peer group.

For girls, the defining personal feature of many who end up in sexually coercive relationships is a history of sexual abuse in childhood. Brown estimates that in the facilities for troubled teens where he works anywhere from 75 to 100 percent of girls have been sexually abused. He notes:

These girls often find themselves in extremely risky sexual situations because sex is the only way they know of getting attention, touching and intimacy. Sometimes they sexually act out because it gives them a feeling of power over 
men that they've never felt or it proves that they now control their own sexuality. Sometimes it is intentionally self-destructive, rooted in their negative view of themselves. Sex in which they are submissive and a partner's need dominates is often all they know. Many times these girls can't tell the difference between touch that is friendly and caring and touch that is intended as a come on.

Similar to the boys, the intense neediness of these girls, which is partly rooted in their personal abuse histories, makes them significantly more vulnerable to gendered stereotypes about sexual behavior. Brown also pointed out how cultural stereotypes of acceptable female behavior also play into the dynamics of coercive sex. "Both boys and girls learn from a young age that good girls are not supposed to admit to wanting sex. The American 'sexual script' says that girls have to pretend 'no' even when they mean 'yes' , which gives boys the perfect excuse to ignore 'no'."

Significantly, this double bind appears to fuel the dynamics of rape in other cultures as well. The authors of a recent research report on child sexual abuse in Zimbabwe make almost the exact same observation:

Women are culturally obliged to say "no" to sex even when they want it and men generally see no problem in exercising some force when pressing for sex. These attitudes facilitate rape in women of any age. They are especially disturbing when considering relationships between older men and young girls, since young girls are traditionally bound to obey older men. Therefore, the dividing line between agreeing and refusing sex is often unclear which makes it more likely the girl will get raped-and carry the blame for it afterwards (Meursing, 1993:16).

These examples illustrate the importance of challenging traditional notions of acceptable "womanhood" in addition to dominant definitions of masculinity. Women must feel free to express their desires openly-both when they want sex and when they don't-if the word "no" is going to be taken seriously. This is not to say that any "mixed message" justifies force or coercion. At the same time, it is important for teenagers and prevention programs to recognize that cultural ambivalence toward female sexuality helps put young women at risk. 
1. DEFINING THE

\section{LINKS}

2. MEN'S VIOLENCE: ORIGINS, MYTHS, AND SCIENCE

3. RESEARCH ISSUES AND METHODOLOGY

A major focus of the second day of the seminar was on researching violence against women. Participants came to the workshop from a variety of backgrounds: some had extensive research training, others were service providers, and still others came from activist or academic backgrounds. All came with a desire to deepen their understanding of violence and coercion through improved and more interdisciplinary research.

Discussion centered on how to improve the research process by encouraging more collaboration between researchers and those who have first-hand knowledge of the issue -the service providers and activists who work with violence on a daily basis. Also of concern was how to make research skills and expertise more accessible to community-based groups who could benefit from better data and more sophisticated means to evaluate their programs. All participants, regardless of their context and background, were interested in approaches that could make the research process more relevant to the tasks of serving victims and preventing future abuse.
THE STATUS OF EXISTING

RESEARCH

LESSONS FROM PAST

RESEARCH

BUILDING COLLABORATION

4.RECOMMENDATIONS

APPENDICES

LIST OF

PARTICIPANTS

BIBLIOGRAPHY 


\section{The status of existing research}

What little is currently known about sexual coercion - its correlates, contexts and consequences - derives from three main areas of inquiry: research emerging in light of AIDS, feminist research on violence against women and sociological research into child sexual abuse and family violence. The general paucity of data on coerced sex is partly a function of the overwhelming lack of research into sexuality in general. It also derives from the tendency of mainstream research to ignore issues of gender and power.

As the exigencies of the HIV epidemic have prompted scientists to explore the details of women's sexual lives, it has become increasingly apparent that many women do not control the timing and nature of their sexual encounters. Research into women's experience with natural family planning has also revealed the limits of women's control over their sexual encounters (Fort, 1989). It has been left to feminists and a handful of sociologists, however, to take up the issue of sexual coercion directly.

Moreover, there has been little cross-disciplinary work to establish the links between sexuality, coercion and reproductive health. Sexuality and violence have been examined in isolation of each other, while the field of family planning has seemingly omitted an awareness of sexuality altogether. Participants strongly stressed the need for more cross-disciplinary research and a greater emphasis on combined quantitative and qualitative work. At this point, prospects for prevention and future theory building are being hampered because of the lack of integration across disciplines.

The group's examination of research issues began with an exercise to explore the limitations of existing family planning research in dealing with subjects such as sexuality and sexual coercion. Traditionally, family planning research has been preoccupied with large-scale quantitative surveys that measure such things as contraceptive prevalence, total fertility and attitudes toward family planning. The field's methodology and problem focus have been dominated by the paradigms of demography and medicine, with little attention to questions of meaning or historical context. Participants were

\section{INTRODUCTION}

1. DEFINING THE LINKS

2. MEN'S VIOLENCE: ORIGINS, MYTHS, AND SCIENCE

3. RESEARCH ISSUES AND METHODOLOGY

THE STATUS OF EXISTING

RESEARCH

LESSONS FROM PAST

RESEARCH

BUILDING COLLABORATION

\section{RECOMMENDATIONS}

\section{APPENDICES}

\section{LIST OF \\ PARTICIPANTS}

BIBLIOGRAPHY

\begin{tabular}{|l|}
\hline If I had to characterize \\
the status of sex \\
research in the United \\
States I would have to \\
say that it is fragmented \\
across many disciplines \\
with few integrative or \\
collaborative efforts; that \\
it remains bound to a \\
problematic focus on \\
risk behaviors in a public \\
health model; and that \\
quantitative \\
approaches are \\
prioritized over \\
qualitative methods. \\
-DIANE DI MAURO \\
\hline
\end{tabular}


asked to "reconsider" from a gender perspective a typical research study on adolescent pregnancy in Africa (see Box 5). What would investigators do differently if they were interested in issues of sexual coercion, power differentials and social change? What questions were not asked? How would the design of the research have to change? This exercise revealed, in a very direct way, the power of applying a gender lens to issues of sexual behavior and control.

$\mathbf{t}$ 


\section{The status of existing research}

What little is currently known about sexual coercion - its correlates, contexts and consequences - derives from three main areas of inquiry: research emerging in light of AIDS, feminist research on violence against women and sociological research into child sexual abuse and family violence. The general paucity of data on coerced sex is partly a function of the overwhelming lack of research into sexuality in general. It also derives from the tendency of mainstream research to ignore issues of gender and power.

As the exigencies of the HIV epidemic have prompted scientists to explore the details of women's sexual lives, it has become increasingly apparent that many women do not control the timing and nature of their sexual encounters. Research into women's experience with natural family planning has also revealed the limits of women's control over their sexual encounters (Fort, 1989). It has been left to feminists and a handful of sociologists, however, to take up the issue of sexual coercion directly.

Moreover, there has been little cross-disciplinary work to establish the links between sexuality, coercion and reproductive health. Sexuality and violence have been examined in isolation of each other, while the field of family planning has seemingly omitted an awareness of sexuality altogether. Participants strongly stressed the need for more cross-disciplinary research and a greater emphasis on combined quantitative and qualitative work. At this point, prospects for prevention and future theory building are being hampered because of the lack of integration across disciplines.

The group's examination of research issues began with an exercise to explore the limitations of existing family planning research in dealing with subjects such as sexuality and sexual coercion. Traditionally, family planning research has been preoccupied with large-scale quantitative surveys that measure such things as contraceptive prevalence, total fertility and attitudes toward family planning. The field's methodology and problem focus have been dominated by the paradigms of demography and medicine, with little attention to questions of meaning or historical context. Participants were

\section{INTRODUCTION}

1. DEFINING THE LINKS

2. MEN'S VIOLENCE: ORIGINS, MYTHS, AND SCIENCE

3. RESEARCH ISSUES AND METHODOLOGY

THE STATUS OF EXISTING

RESEARCH

LESSONS FROM PAST

RESEARCH

BUILDING COLLABORATION

\section{RECOMMENDATIONS}

\section{APPENDICES}

\section{LIST OF \\ PARTICIPANTS}

BIBLIOGRAPHY

\begin{tabular}{|l|}
\hline If I had to characterize \\
the status of sex \\
research in the United \\
States I would have to \\
say that it is fragmented \\
across many disciplines \\
with few integrative or \\
collaborative efforts; that \\
it remains bound to a \\
problematic focus on \\
risk behaviors in a public \\
health model; and that \\
quantitative \\
approaches are \\
prioritized over \\
qualitative methods. \\
-DIANE DI MAURO \\
\hline
\end{tabular}


asked to "reconsider" from a gender perspective a typical research study on adolescent pregnancy in Africa (see Box 5). What would investigators do differently if they were interested in issues of sexual coercion, power differentials and social change? What questions were not asked? How would the design of the research have to change? This exercise revealed, in a very direct way, the power of applying a gender lens to issues of sexual behavior and control.

$\mathbf{t}$ 


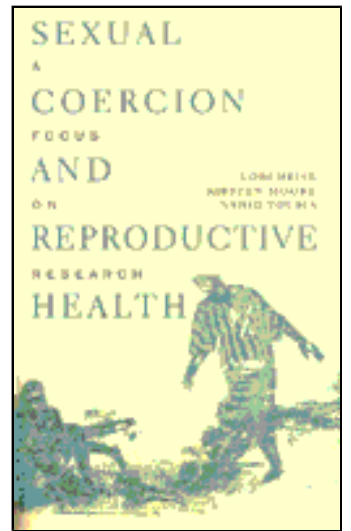

The seminar continued with panel presentations from four investigators who had first-hand experience researching sexual coercion in different settings. Since methodology in this area is essentially new and uncharted, panelists were encouraged to share what they learned about how to do such research, rather than their research results per se.

Dr. Mary Koss began by sharing her experience in undertaking large-scale prevalence surveys on sexual coercion and rape in the United States. Koss described her work as the "bean counting" approach to research, but emphasized the importance of gathering scientifically defensible estimates of a problem in order to build political support for action. Reviewing what she has learned in her many years of research, Koss emphasized the importance of asking multiple, behavioral specific questions when probing for sexual abuse. "Rape appears under many guises," notes Koss, "and consequently a number of investigators have concluded that you need to have multiple questions that ask people about specific behaviors in order to stimulate people's recall."

Elizabeth Shrader made similar points when discussing her research on domestic violence in a peri-urban area of Mexico City. Shrader worked with CECOVID, a grassroots women's organization in Mexico, to generate prevalence data on domestic violence in order to build support for a battered women's shelter. Interviewers visited 390 random households in a low-income neighborhood outside of Mexico City. Shrader found that even in a "door to door" survey women were willing to answer explicit questions regarding their experience with violence. Although the subject matter was not a barrier to disclosure, privacy was. Women who had a child or other family member present during the interview were somewhat less forthcoming
FOREWORD

INTRODUCTION

1. DEFINING THE LINKS

2. MEN'S VIOLENCE: ORIGINS, MYTHS, AND SCIENCE

3. RESEARCH ISSUES AND METHODOLOGY

THE STATUS OF EXISTING

RESEARCH

LESSONS FROM PAST

RESEARCH

BUILDING COLLABORATION

\section{RECOMMENDATIONS}

\section{APPENDICES}

\section{LIST OF \\ PARTICIPANTS}

BIBLIOGRAPHY

When advocating for a cause or trying to set up services, it is important to show how your problem is significant and as important as other problems with which you are competing for resources.

-MARY KOSS 
Shrader's questionnaire included general

questions about whether women felt they had experienced a violent relationship at some point in their life. Then it used specific behavioral probes to compare the woman's selfassessment/definition of abuse with an objective measure of what types of behaviors she had endured. Shrader noted that women immediately recognized physical abuse as battery, but many did not classify psychological and sexual abuse as "violence." Nonetheless, when asked, these women identified these behaviors as extremely painful even though they did not "fit" their internalized definition of "violence."

The Mexico survey emphasizes the importance of combining questions that allow researchers to compare women's own internal definitions of violence with objective measures of abuse. Asking behavioral specific questions (e.g. Has your partner ever forced you to have sex when you didn't want to?) allows data to be compared across situations without introducing personal or cultural bias. At the same time, it is important to collect information on how women interpret and experience specific actions. Does the woman categorize the behavior as violent? Does she find it painful or harmful? Does she think she deserves such treatment? How did she respond?

It is important to recall in this context that cultural and personal definitions of violence are frequently a "moving target." As discussed earlier, many women come to interpret what happened to them as rape" or sexual violence only after being exposed to a language and analysis that recognizes their right to live free of such abuse, Even though the specifics of an event remain the same, a woman's interpretation of the event and its meaning may well change over time. Women are especially likely to "accept" certain levels of abuse as normal" when immersed in cultures that grant men the implicit right to control and censure female behavior.

The third panelist, Dr. Gail Wyatt from UCLA, recently completed a national survey of sexual decisionmaking and nonconsensual sex among men and women in Jamaica. This study represents one of the first attempts to investigate, in a developing country setting, consensual and nonconsensual sexual experiences across the life course. Wyatt and her Jamaican colleagues emphasized the 
importance of pilot testing both the instrument and the proposed research methodology before proceeding to a full-scale investigation. In this case, the research team learned the best type of interviewers to use through their pre-test. Most individuals preferred census workers to STD caseworkers or nurses, largely because they perceive census workers as professional and mature. People were willing to talk to either men or women but they definitely preferred to talk with someone from their own class. The pilottesting also revealed that interviewers could not successfully canvass their own neighborhoods. As Wvatt notes, "People feel more comfortable if they do not have to reveal such intimate details to people they know."

The final presenter was Ellen Weiss, director of the Women and HIV research project of the International Center for Research on Women (ICRW). With funding from the U.S. Agency for International Development (USAID), ICRW has funded 17 research projects worldwide to collect information on women's attitudes, beliefs and experiences regarding sexuality and HIV/AIDS. The resulting projects have used a combination of innovative methods to encourage frank disclosure by women, men and adolescents about their sexual behavior.

In general, project researchers found that group discussions were useful for obtaining data on social norms and behaviors, but were less successful for getting people to articulate their own personal experiences and behaviors. Researchers from Mauritius, for example, learned of the phenomenon known as "light sex" (a man rubs his penis against the vagina or penetrates to the point of pain) as a result of sernistructured interviews, but this issue was never discussed in focus groups. Generally, one-on-one interviews, with or without structure, were the most effective means at getting people to reveal intimate personal details. As one investigator reported, "Women would automatically bring up most of the issues that we wanted to learn about, but they will do so in their own way and own time."

Weiss emphasized the fluidity and iterative nature of this type of research: "Often researchers had to proceed by trial and error to figure out which research approach would work." The difficulty of getting candid answers on such a sensitive topic actually served to promote experimentation with many unconventional research tecniques. Researchers used such 
things as picture cards or incomplete stories to encourage respondents to speculate about what would happen in their society. Researchers in Zimbabwe, for example, used a picture of a school girl being eyed by an older man in a big car to encourage young women to discuss the phenomenon of "sugar daddies," (men who pay the school fees of young girls in return for sexual favors).

In the ICRW projects, the choice of interviewers was typically determined by the expected outcomes of the project (e.g. will it lead to an intervention). For example, sometimes it was helpful to have a principal investigator from outside of the community, who could as questions or push for clarifications based on her status as an outside (e.g. I don't understand, please explain it to me). On the other hand, projects undertaken in collaboration with existing community-based organizations often used peer interviewers, generally with great success, These interviewers made a valuable contribution to the research process and were useful for bringing the information back to the, community and helping it organize for change.

Weiss also brought up the issue of the therapeutic benefit to women of one-on-one interviews and the ethical responsibility of researchers to prepare themselves to deal with the emotional fallout, of the interview. Women involved in the research project from India for example, repeatedly said how grateful they were to the interview team: no one had ever sat and talked with them for such a period of time or asked them to talk about their sexual experiences. In fact, all', researchers present confirmed that gratitude was the dominant', response of the respondents in their studies. Far from being unwilling to talk about their experience, they were appreciative and relieved that someone had finally asked.

The sensitive nature of the topic and the emotional power of, memories long withheld raises the possibility that the interview process may overwhelm some respondents. Shrader noted that probings into sexual abuse during marriage or childhood were particularly likely to evoke powerful responses. Interviewers have to be prepared to suspend the formal interview momentarily (or completely if necessary) to offer sympathetic support to the respondent.

Participants also agreed that researchers had an obligation to provide referral information to

\begin{tabular}{|l|}
\hline A well-trained \\
interviewer who is \\
supportive, responsive \\
and gives the message \\
that abuse is wrong can \\
have immeasurable \\
value for women who \\
have been abused. \\
- ELLEN WEISS \\
\hline
\end{tabular}


women who agreed to participate in violencerelated studies. Shrader recommended producing a small card that could easily be hidden to provide information to women about available support and legal services. Wyatt noted that even women who did not appear obviously upset during an interview may have a delayed reaction, so all women should be provided with such information. One respondent in the Jamaica study called the interviewer at home late at night thoroughly distraught after experiencing a delayed reaction to recalling her childhood abuse.

Participants discussed at length other ethical obligations of researchers who embark on investigations of gender-based abuse. A primary ethical obligation of researchers engaged in violence work is to consider women's safety at all times. Researchers should not ask women questions about abuse in front of other family members, especially men. In a phone interview, a woman should always be informed about the nature of the survey and asked if it is safe for her to talk. Information should not be sent to a woman's home that would reveal her participation in a study of sexuality or violence. Such actions could put women living in abusive situations at further risk.

Investigators also spoke of their obligation to their research teams in terms of training and emotional support. As Shrader observed of their experience in Mexico, it is important to recognize that members of the research team may have their own histories of abuse that must be addressed if they are going to be effective at their jobs. "We started with 40 social workers on loan from a clinic to train as interviewers," notes Shrader. "Maybe 30 women came to the first day of training. On the second day 25 women came back. Eventually we were down to 8 women." What the Mexican team realized over time was that many of the social workers themselves were living in abusive relationships. "We had an incredible attrition rate," notes Shrader, "because the women could not confront the reality of their own abuse and we did not anticipate this problem in our training."

Closely related is the importance of providing ongoing emotional support for the interviewers and others who had to confront stories of violence on a daily basis - an issue that several investigators emphasized. Several projects had instigated weekly support groups where those doing interviews could discuss the impact that women's stories were having on their personal lives. Research personnel frequently reported a "spillover" effect into their own relationships in which built-up anger toward men began to interfere in their relationships with male colleagues and partners.

This is equally true for the principal investigators as for the research staff. All researchers 
necessarily bring to this work their own personal thoughts, feelings and experiences about sexuality and violence. During the seminar, the group participated in an exercise that showed clearly that there are no sharp distinctions between the "researched" and the "researcher" on issues of abuse.

On the first day of the serninar, each participant was asked to briefly describe, on two separate index cards, their best sexual experience and their worst sexual experience, along with the age at which it occurred (different colored cards were given to men and to women). Overnight, the cards were pasted on a butcher-paper timeline above or below the appropriate year (the best experiences were positioned below the line and the worst above it).

The next morning, when the group reviewed and analyzed its "Sexual Lifeline, (figure 4)" participants realized that many of the examples of coercion discussed the day before were present in their own experiences as well. Many of the negative sexual experiences were connected with violence, alcohol and premature sexual activity, while the more pleasurable experiences ranged from the physically satisfying to the emotionally and spiritually significant. Although negative experiences occurred throughout the tirreline, on the whole, they were grouped earlier on the continuum. Several people also noted that it seemed easier to identify and define the worst experiences, while the best experiences were less easily described. As one person observed, we have "no language for the pleasure."

One notable gender difference was the extent to which men's unpleasant experiences had to do with misjudgment or embarrassment whereas women's unpleasant experiences had to do with forced sex. Women's worst sexual experiences were also much younger, often in childhood and adolescence. Aside from reminding the group that sexual coercion is not just something "out there" to be studied, the exercise proved - in the words of Steve Brown - that "many of us have profoundly personal reasons that brought us to this work."

Finally, many of the researchers in the room spoke candidly about the personal and professional toll exacted on them by undertaking work on violence. Because research on genderbased abuse is largely perceived as academically irrelevant and/or threatening, those who research the topic are often professionally marginalized and ridiculed. Some are actually threatened. Peggy Sanday shared stories, for example, of how her researchers received death threats after making inquiries into fraternity gang rape on U.S. college campuses. "In any research on sexual coercion, in addition to the scientific issues, there is always the political issue," she noted. "Violence, 
isolation or threats against researchers can

have a chilling effect on the research

conducted," Or, as Gail Wyatt observed: "You

take a real hit for doing this kind of research." 


\section{Chapter 3}

\section{Building Collaboration}

The final panel of the day was a roundtable discussion among service providers and activists about bow to overcome the historical tension between researchers and community-based organizations. As panel members explained, many grassroots groups had experiences with researchers in the past that left them distrustful of requests to "collaborate" on research. Frequently, researchers appear to be more concerned with their own professional advancement than with the well-being of the woman being studied. The power imbalance between researcher and subject becomes especially problematic when Northern researchers conduct research in Southern countries. Panelists noted that, not uncommonly, research results from developing countries get reported at international conferences only to remain unavailable and unknown in the host country.

At the same time, all panelists could give examples of research collaborations that were highly positive. In these examples, the researchers involved the community-based groups. and service providers in the formulation of the research questions. The investigators treated the community-based organization as a true partner, as opposed to a "site for their research." And most importantly, the researchers recognized the practical expertise that comes from years of living with or working on an issue.

"It works best when there is mutual learning on both sides," noted Gita Misra of SAKHI, a community group that works with South Asian battered women in New York City. SAKHI encourages anyone undertaking research on abuse in the South Asian community to participate in their 15-20 hour intensive training course community volunteers.

In addition to generating more meaningful findings, collaboration between activists and service providers often means the re, have a better chance of being applied in the real world. Service organizations can reevaluate strategies or design different Interventions based on research results. Local women's groups can use the generated to advocate changes in law and policy. Arid exposure activists can inspire professionals and academics to become change agents in their own communities: "As a result of my work as a volunteer in a battered women's shelter and my research on the prevalence of abuse and battering within Nordic countries," notes Norwegian physician Berit Schei, "I am now interested in the question of to introduce ... the subject of physical and sexual abuse into the curricula of medical schools arid the training of gynecologists."

Indeed, many of those who research sexual coercion are them selves a hybrid between researcher and activist. "We who do work this area are often activists just by the nature of the topic," says Ritchie, a long-time activist who now conducts research on violence against women in the United
FOREWORD

INTRODUCTION

1. DEFINING THE LINKS

2. MEN'S VIOLENCE: ORIGINS, MYTHS, AND SCIENCE

3. RESEARCH ISSUES AND METHODOLOGY

THE STATUS OF EXISTING

RESEARCH

LESSONS FROM PAST

RESEARCH

BUILDING COLLABORATION

\section{RECOMMENDATIONS}

\section{APPENDICES}

\section{LIST OF \\ PARTICIPANTS}

BIBLIOGRAPHY
I was a newly trained physician working as a gynecologist in a small Norwegian town when a group of women approached me asking me to share information on the consequences of physical and sexual abuse of women. I accepted and then went to read up on the topic; I found there was very limited information so I began to volunteer at a battered women's shelter. It would have been impossible for me to do my research without working in a shelter. The practical imnlications of mv work 
States. Most participants felt that this"mixed heritage" was beneficial both to their own work and to those whose lives they were working to improve. Also important is seeking input from victims/survivors themselves. As Ritchie observed, "I have been as influenced in my work by having a constant input from the I work with as I have by conducting periodic computer searches of the literature."

Although all participants acknowledged the benefits of cell.', oration, a few raised notes of caution about the possibility of cooperation and the danger of oversimplifying the process. Several participants noted it is important that advocates maintain their independence. "Advocates should never compromise their role as advocates because there are things they can say and do which those of us on the inside of big bureaucracies cannot." Moreover, issues of power and resources can often frustrate dreams of "collaboration." As Irma Saucedo from El Colegio de Mexico pointed out, "Although we we have good intentions, resources are a problem. Our experience has shown that conducting collaborative research is extremely time consuming, more so than is typically expected or allowed for research organizations and their funders."

Educating donors, then, is a critical part of the task ahead. Representatives from funding agencies emphasized the Importance of having such needs expressed by people from outside of donor agencies - from recipients or potential recipients of funds - in order to convince executive boards and management that the extra time and expense of collaborative, interdisciplinary research is worth the money. Several people noted the need for intermediate-level organizations to serve as "pass throughs" to communitybased groups for larger sums of money provided by donor agencies. MATCH International in Canada was presented as a model for this type of approach. MATCH receives money from the Canadian Development Agency and then redistributes it in small grants to women's organizations overseas.

Ultimately, though, words like "partnership" and "collaboration," are easy to say and difficult to achieve. As Nahid Toubia points out, these words have been adulterated through years of overuse. In response, she encouraged everyone to confront the issue of collaboration on a deeply personal level. "At the end of each day, ask yourself: How much have I listened? How much have I talked down? How much have I incorporated what I have heard? How much have I shared information and resources?" If everyone were guided by this moral inventory, the potential for true collaboration would move immeasurably closer. 


\section{Chapter 4}

\section{Recommendations}

In the closing hours of the symposium, participants broke into smaller groups to develop more specific recommendations for future work on sexual coercion and women's reproductive health. One group focused on a tentative research agenda. A second group developed a list of "process" principles to guide future researchers. And a third briefly discussed how concern for violence and coercion could be integrated into reproductive health practice. Participants agreed that this final topic could easily justify a symposium in its own right and recommended a similar event be organized to focus specifically on reproductive health providers and what they can and should do to respond to this problem.
INTRODUCTION

1. DEFINING THE LINKS

2. MEN'S VIOLENCE: ORIGINS, MYTHS, AND SCIENCE

3. RESEARCH ISSUES AND METHODOLOGY

\section{RECOMMENDATIONS}

TOWARD A RESEARCH AGENDA ON SEXUAL COERCION AND

REPRODUCTIVE HEALTH

THE ROLE OF HEALTH PRACTITIONERS

APPENDICES

LIST OF

PARTICIPANTS

BIBLIOGRAPHY 
Chapter 4

TOWARD A RESEARCH AGENDA ON SEXUAL COERCION AND REPRODUCTIVE HEALTH

Because of the enormous variability across settings and cultures, the group felt it would be more appropriate, at this stage of knowledge, to suggest basic principles to guide research on sexual coercion, rather than recommend particular approaches to measuring sexual violence and abuse. Although more detailed methodological recommendations are clearly needed, participants felt it was beyond the group's capacity to make such detailed recommendations within the time available. Participants recommended that a separate group be convened to develop a methodological manual for researchers about doing research on sexual coercion cross-culturally. In the meantime, participants developed a list of generic principles to guide international research in the area of sexual violence and abuse (see Box 6). In addition, another small group developed a list of priority areas in need of research. The final agenda included six primary research domains including the following:

1. Context of violence. Studies are needed to address the sociocultural contexts that shape and support sexual coercion, including studies of:

1. sexual values, attitudes arid scripts;

2. gender-based sexual roles; and

3. economic and.cultural practices that give rise to violence.

2. Basic epidemiologic research. To establish the dimension of the problem and build political support for a response, researchers must document the prevalence of the problem through community-based surveys in a variety of settings. So that basic epidemiologic data are comparable across settings, researchers must develop standardized approaches to defining and measuring different types of abuse. Questions related to violence and coercion should be integrated into ongoing research related to AIDS, sexuality and reproductive health.

3. Interpretations and meaning. Popular myths about rape, its perpetrators and victims and how such myths serve to legitimize violence, should be documented across cultures. Urgently needed are culturally sensitive portraits of violence and its effects from the perspective of its victims. Although the physical and emotional symptoms of trauma appear to be similar across cultures, groups differ in the meanings attached to these symptoms and to their preferred method of healing.

4. Consequences of coercion for reproductive health. Hypothesized links between sexual coercion

\section{INTRODUCTION}

1. DEFINING THE LINKS

2. MEN'S VIOLENCE: ORIGINS, MYTHS, AND SCIENCE

\section{RESEARCH ISSUES} AND METHODOLOGY

\section{RECOMMENDATIONS}

TOWARD A RESEARCH AGENDA ON SEXUAL COERCION AND

REPRODUCTIVE HEALTH THE ROLE OF HEALTH PRACTITIONERS

\section{APPENDICES}

LIST OF

PARTICIPANTS

\section{BIBLIOGRAPHY}

Box 6

Principles to Guide Research on Sexual Coercion

To ensure that research undertaken on violence against women is as directly useful as possible, respects women's needs and safety and is

culturally informed, researchers should do the following:

1. Work from a theoretical framework that recognizes gender and power as central to the understanding of sexual violence.

2. Recognize that abuse and coercion exist along a

continuum.

3. Respect the value of

experiential knowledge in

addition to academic training

4. Consult with local women's

groups working on violence

issues as early as possible in

the research process, preferably

before research questions are fully framed.

5. Provide all respondents with referral information where they can receive additional psychological or legal help should they need it.

6. Strive to make sure that their research makes a difference in the real world.

7. Ensure that their findings are accessible and intelligible to as broad a range of constituencies as possible, including the community under study, service providers, policy makers and the activist community.

8. Actively make the findings available to these 
and reproductive health problems such as chronic pelvic pain, inability to negotiate condom use and unwanted pregnancy must be further explored and documented. Studies on the emotional and physical health consequences of rape must be extended to settings in which multiple sources of trauma are present, such as in conflict and refugee situations.

5. Processes that maintain violence. The major systems of criminal justice, law, media and medical care play a role in maintaining rape by procedures that deny victimization, create obstacles to obtaining validation or care, and decontextualize injury and illness. This research area needs studies that delineate these processes, including how laws are enforced, how systems handle victims (e.g. in the courts or in emergency rooms), how the media report rape, and the biases of key decision makers (e.g. police, judges, editors, physicians). In addition, research is needed into how homophobia enforces masculine gender role identity based on dominance and aggression.

6. Intervention strategies. Little is known about how women and their social networks are currently dealing with sexual violence. This information is essential to formulate culturally appropriate responses to sexual violence. By documenting indigenous approaches to healing the victim and addressing the perpetrator, researchers can help prevent "overmedicalizing" the problem. In many countries, sexual violence is viewed as a community problem for which there must be a community response.

There is also great need for studies to evaluate the impact of various interventions. Presently, there is little information available on the relative effectiveness of different approaches to responding to and/or preventing violence. coristiuenicies.

9. Recognize that participation in research on violence against women can have personal consequences for interviewers and other members of the research team, including placing their lives and careers in jeopardy.

10. Work collaboratively with men who share a commitment to ending gender - based abuse and who are willing to mentor like-minded men. 


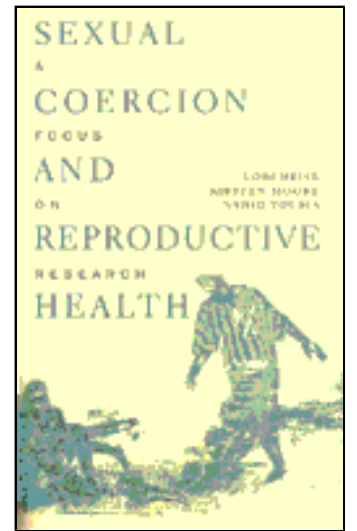

Reproductive health providers have a responsibility and an opportunity regarding their response to gender-based abuse. They have a responsibility as practitioners to be cognizant of issues around women's safety and to be aware of the role that abuse may play in the etiology of certain reproductive health complaints. They also have an important opportunity. Because of their ongoing contact with women, providers can either be an important source of support and referral for victims or they can exacerbate the situation through insensitive and judgmental behavior.

Participants in the working group on reproductive health services noted that family planning clinics and primary care settings were the perfect environments for asking sensitive questions about abuserelated issues. Providers are generally granted greater "social permission" to ask personal questions about matters related to reproduction and sexuality and can adopt an attitude of clinical interest rather than moral inquiry. Contrary to what one might expect, women around the world have proven remarkably willing to answer questions about abuse if asked in an understanding and nonjudgmental manner.

Participants who had experience introducing questions about abuse into health-care settings noted that women were deeply appreciative of a chance simply to talk. As Elizabeth Shrader observed, "Sympathetic treatment and a space to talk can facilitate 'healing."' Family planning workers can perform an important service simply by breaking the silence surrounding abuse and putting women in contact with individuals and groups better prepared to deal with their violence-related problems. Even where no services exist, a provider can emphasize that no one deserves to be beaten or to be blamed for being raped. This challenge to dominant norms can help women dispense with self-blame and move toward positive action.

Reflecting on what would be feasible in the short to medium term, participants recommended the following programmatic initiatives for reproductive health programs and providers:

1. Be aware. Be aware that spousal consent policies and condom use may put a woman at risk of reprisal; be aware that a pregnant 14 year old may be a victim of incest or sexual coercion; be aware that a woman with unexplained chronic pelvic pain may have been a victim of sexual abuse or rape; be aware that community family planning workers asked to travel from village to village may be at risk of sexual assault.

2. Train staff. Training about abuse should be integrated into larger training programs designed to sensitize staff to issues of gender and sexuality.
FOREWORD

INTRODUCTION

1. DEFINING THE LINKS

2. MEN'S VIOLENCE: ORIGINS, MYTHS, AND SCIENCE

3. RESEARCH ISSUES AND METHODOLOGY

\section{RECOMMENDATIONS}

TOWARD A RESEARCH AGENDA ON SEXUAL COERCION AND

REPRODUCTIVE HEALTH

THE ROLE OF HEALTH PRACTITIONERS

\section{APPENDICES}

LIST OF

PARTICIPANTS

BIBLIOGRAPHY 
Presently most staff avoid talking with clients about sex and/or abuse because they feel uncomfortable themselves with these topics. Providers must be helped to confront their own biases and insecurities so that they can better serve their clients.

3. Provide basic screening and appropriate responses. The role of family planning providers should be to screen clients for physical and sexual abuse and then refer them to available services. Screening should ideally occur within the context of asking more general questions about the woman's sexual/gynecological history and provide women with as much privacy as possible.

4. Network and refer. Family planning clinics should contact area women's groups to familiarize themselves with local services available for women living in abusive situations. Often advocacy groups and crisis centers will have information pamphlets or posters that can be prominently displayed in clinic waiting areas. They are also frequently available to train clinic staff on the dynamics of abuse.

5. Organize self-help support groups. Clinics and other service centers can make a significant contribution simply by making space available for women to meet on their own to share their problems and self-help strategies. In controlled studies, selfhelp support groups have been shown to improve the self-esteem, psychological health and physical wellbeing of a wide range of participants, from grieving spouses and parents who have lost children (Lieberman and Videka-Sherman, 1986) to survivors of open heart surgery (Lieberman and Borman, 1979). Research also suggests that in many settings, peerled support groups are as successful at achieving positive outcomes as professionally led groups (Toseland et al., 1990).

6. Consider staff. Clinic directors and staff trainers should be sensitive to the fact that some of their own staff may be victims of abuse. 
Adapted from Susanna Rance, "Control and Resistance: Empowering Strategies in the Reproductive Lives of La Paz Market Women."

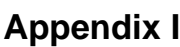

COERCION IN THE LIVES OF AYMARA MARKET WOMEN

Empowerment of Women Research Program, Bolivia Report No. 1.

Arlington VA: JSI Research and Training Institute, 1994.
FOREWORD

INTRODUCTION

1. DEFINING THE

LINKS

2. MEN'S VIOLENCE:

ORIGINS, MYTHS, AND

SCIENCE

3. RESEARCH ISSUES AND METHODOLOGY

\section{RECOMMENDATIONS}

women interviewed in this study grew up in households where high fertility, female submission and male dominance were the unquestioned order of things. From infancy, girls were trained to accompany and help their mothers with domestic chores and child care, while their brothers, carefree and uncaring, went out to play. Women suffered, cried and put up with abuse. Men shouted, laid down the law, were unfaithful and spent their wives' money on drink. Violence was common. One woman's father killed two of her younger siblings.

While mothers warned vaguely about the risk of pregnancy, fathers policed adolescent girls' comings and goings and administered physical punishment if they stayed out late. In some cases, being caught with a boy was sufficient to signal dismissal from the parental home, with male authority over the woman being formally transferred from father to husband. In others, fathers locked adolescent daughters in, only consenting to marriage when they had proved their determination and womanhood by escaping more than once from the home.

This established order of things clearly determined women's reproductive lives. Mothers passed on the message that childbearing was the inevitable result of living with a man.

A mother's duty was to cater to her son's foibles and care for him in every way: "He's a boy, after all." When a boy grew up, it became his wife's role to "pamper him" and understand him in everything. "It's like they say- men are like babies."

Despite their oppressive upbringing, some of the women interviewed eventually rebelled against this notion: "Men think they can have everything in the world because God made them like that," said a woman of 38 whose father had married her off when she was 14 , even before she had started her periods. "They think that because they're men, they can do anything. That's what they think-but it's not like that."

Half of the total number of interviewees reported taking decisive action to counter domestic and sexual violence. In two-thirds of these cases, the women packed up and left abusive partners for periods of weeks or months. In a third

\section{APPENDICES \\ Appendix I \\ Appendix II \\ $\frac{1}{2}$ \\ $\frac{2}{3}$ \\ 3 \\ 4 \\ 5}

\section{LIST OF}

PARTICIPANTS

BIBLIOGRAPHY 
of the cases, the women reacted by hitting back, using their own force or wielding heavy objects, a strategy that proved effective in dissuading future attacks. Half of the women who retaliated against marital abuse appealed to family members or other allies to sanction the partner's behavior. A small minority reported incidents of domestic violence to the police or took their partners to court, while an even smaller number opted for permanent separation or divorce.

"Sometimes we have terrible fights," said one woman who had lived with a violent partner for 14 years. "Now I tell him. 'I used to put tip with your violence, but not any more.'... I used to be afraid, but now I say, 'What on earth is all this about?' It's only now that I'm waking up (becoming aware) what a fool I was before."

Another interviewee had decided to get an IUD four years previously, having been unable to resist her husband's violence and insistence on having unprotected sex, which led to a series of unwanted pregnancies. "You can't be with the man and not get pregnant," she said. "I know what my husband is like, and I don't want to suffer ... so I decided to take care, myself. I got myself cured (had an IUD inserted)."

Although she no longer feared pregnancy, this woman continued to have problems with her husband's insistence on sexual relations, which she found repugnant. This case illustrates a dilemma faced by many women in the study: the desire to free themselves from the risk of unwanted pregnancy through the use of reliable contraception, without simultaneously exposing themselves to frequent pressure for sex, which they often found not only unsatisfying but also brutal and painful.

Some women declared that they did riot need contraception, since they were determined to have no more sex. When women find sexual relations unsatisfying or unpleasant, they are less likely to seek reliable contraception, since this puts an end to need for abstinence and gives the partner license to have sex as frequently as he wishes.

The minority of interviewees who did use modern contraceptive methods had several characteristics in common. All were in their thirties. Five out of the seven women had aborted at least once, and three had given birth to one or more children who died in infancy. While many of the women interviewed reported violence from their partners, the contraceptive users were especially prone to counter such behavior through decisive actions, including recourse to lethal measures, in defense of their own integrity.

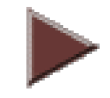


Appendix II

CONFRONTING ABUSE: A GUIDE FOR HEALTH CARE PROVIDERS

Adapted with permission from Marian Sassetti, "Domestic Violence,"

Primary Care: Clinics in Office Practice. 20(2):289-305, 1993.

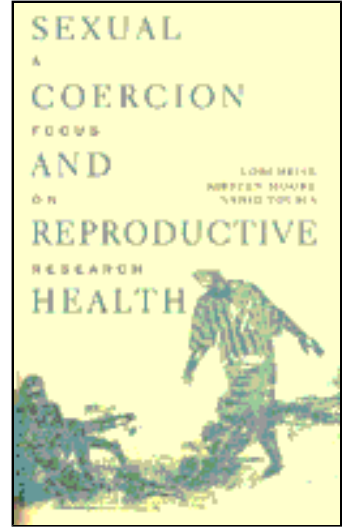

Domestic abuse is most commonly the abuse of a woman by a man. Therefore this guide refers to the perpetrator as a male and the victim/survivor as a female. However, one should never rule out abuse simply on the basis of gender women can hurt women (e.g. mothers abusing daughters) and more rarely, women can hurt men.

Click on the section below you are most interested in;

- Screen all patients/clients for abuse.

- Conducting the interview

- Questions you need to ask

- Acute and long term care of the battered woman

- Take care of yourself.
MEN'S VIOLENCE:

ORIGINS, MYTHS, AND SCIENCE

3. RESEARCH ISSUES AND METHODOLOGY

FOREWORD

INTRODUCTION

1. DEFINING THE LINKS

4.RECOMMENDATIONS

LIST OF

PARTICIPANTS

BIBLIOGRAPHY 
Appendix II

CONFRONTING ABUSE: A GUIDE FOR HEALTH CARE PROVIDERS

Adapted with permission from Marian Sassetti, "Domestic Violence,"

Primary Care: Clinics in Office Practice. 20(2):289-305, 1993.

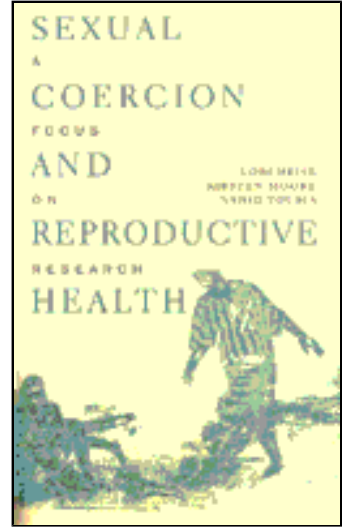

1. The woman presents with chronic, vague complaints that have no obvious physical cause. More sexually and physically abused women seek care because of persistent headaches, chronic pain, sleep disturbance and other vague symptoms, than because of injury.

2. She is pregnant.

3. She has had a miscarriage or abortion.

4. Her injuries don't match her explanation of how she sustained them.

5. Her husband is overly solicitous or controlling.

6. She is suicidal, or has a history of attempted suicide.

Because abusers often accompany women to the doctor in order to keep them from disclosing, always separate a woman from her husband or kin before probing for abuse. Generally this can be done by asking others to leave "until the patient is examined." If your facility cannot accommodate private interviews or exams, do not put a woman in greater danger by refusing to believe her story, no matter how implausible. If her abuser is with her, her life may depend, quite literally, on you accepting her explanation of her injuries. ORIGINS, MYTHS, AND

SCIENCE

3. RESEARCH ISSUES AND METHODOLOGY

FOREWORD

INTRODUCTION

1. DEFINING THE

\section{LINKS}

\section{RECOMMENDATIONS}

\section{APPENDICES}

Appendix I

Appendix II

$\frac{1}{2}$

2

3

4

5

\section{LIST OF}

PARTICIPANTS

BIBLIOGRAPHY 
Appendix II

CONFRONTING ABUSE: A GUIDE FOR HEALTH CARE PROVIDERS

Adapted with permission from Marian Sassetti, "Domestic Violence,"

Primary Care: Clinics in Office Practice. 20(2):289-305, 1993.

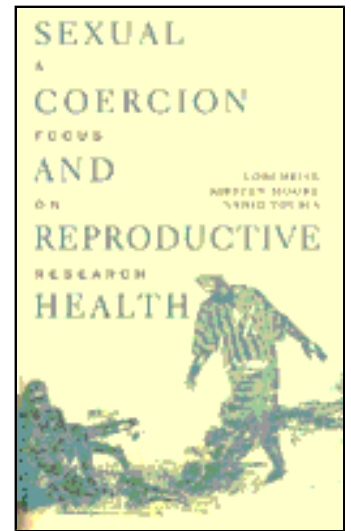

1. Do not be afraid to ask! Contrary to popular belief, most women are willing to disclose abuse when asked in a direct and non-judgmental way-indeed many are secretly praying for someone to ask. You can gently state: "Being in relationships is often very difficult and can cause us lots of pain and suffering. Many women who feel the way you do are suffering from violence in their homes. Could this be happening to you?" or "Can you tell me if anyone is hurting you or making you feel bad about yourself?"

2. Create a supportive environment. Let her tell her story. State very clearly that she is not crazy and that no one deserves to be beaten or raped no matter what the circumstances. This reassurance is crucial and cannot be overstated, as simplistic as it may sound. Acknowledge her feelings and let her know that she is not alone. Commend her for taking the first step toward improving her life and her children's lives. Affirm that she did the right thing by telling someone about the crime that is occurring in her life.

3. Remain nonjudgmental and relaxed. Most battered women are exceedingly good at picking up nonverbal cues as to how people are reacting to them. (Indeed, many women try to escape episodes of battering by learning to "read" the mood of their partner.) Remember, the most important step to ending the violence is achieved the moment you allow the woman to tell her story.

4. Explain that she has medical and legal rights. The penal codes of almost all countries criminalize rape and physical assault, even if there are no specific laws against domestic violence. Try to find out what legal protections do exist in your country/state for victims of abuse, and where women and children can turn for help in enforcing their rights. Most legal systems have some type of restraining order/peace bond that can be used to order a man to stop abusing his partner. In a growing number of jurisdictions, special legislation has been passed to permit judges to order a wider range of remedies including barring the man from the conjugal home, mandating that he pay maintenance and child support, and mandating that he seek treatment. Be especially sensitive to women's fears of "losing" their children should she leave her partner. Investigate your local child custody laws so that you can allay these fears, where the law is on her side.

5. If pressed for time, establish an alliance and schedule
MEN'S VIOLENCE: ORIGINS, MYTHS, AND SCIENCE

1. DEFINING THE LINKS

\section{RESEARCH ISSUES
AND METHODOLOGY \\ 3. RESEARCH ISSUES
AND METHODOLOGY}

\section{RECOMMENDATIONS}

\section{APPENDICES}

Appendix I

Appendix II

$\frac{\frac{1}{2}}{\frac{3}{4}}$

\section{LIST OF}

\section{PARTICIPANTS}

BIBLIOGRAPHY 
a return visit in the very near future. Tell the woman you are glad that she told you about the problem and that you want to spend more time with her addressing this very serious issue. Find out if she is in immediate danger and needs urgent intervention. If there is no emergency, tell her that you are concerned about her health and wellbeing and that you want a follow-up visit with her to fully discuss and address the issue. Make sure she leaves with, at the very least, the number of a local crisis center she can call. 
Appendix II

CONFRONTING ABUSE: A GUIDE FOR HEALTH CARE PROVIDERS

Adapted with permission from Marian Sassetti, "Domestic Violence,"

Primary Care: Clinics in Office Practice. 20(2):289-305, 1993.

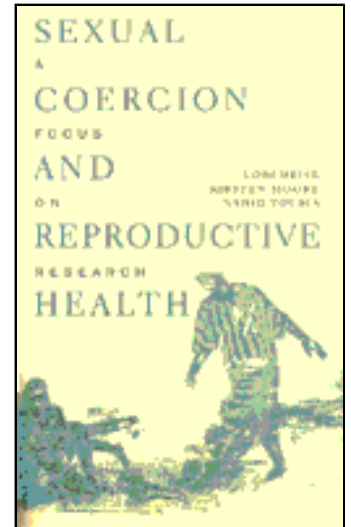
local women's shelter or crisis center.

2. Are there children involved in the abuse? If there are, make sure that you evaluate them now or in the immediate future. If abuse has occurred, you may be mandated to report it (depending on the laws in your state/country), but you must provide for the safety of the woman because reporting "child abuse" may exacerbate the battering situation.

3. Does her partner use drugs or alcohol? Drugs and alcohol do not cause violence, but some women are more at risk of attack when their partner is tinder the influence. Ask her whether she associates her partner's violence with his drinking or drugging. If so, her partner's condition can provide an important cue for her to take protective measures, such as spending the night with friends or family. Generally it is unwise to try to discuss any issue of import when a man is drunk or high; encourage her to wait until he is sober to bring up issues, especially concerns regarding his drinking or drug use.

4. Does she use drugs or alcohol to help her cope? These drugs can blunt women's abilities to make rational decisions and can lead eventually to addiction. The drugs can also be used for suicide, as below.

5. Has she ever attempted or thought of suicide? Make sure you ask if she has a plan if she says she has thought of suicide. The situation becomes urgent once an individual has formulated a plan for suicide because he or she typically acts on it in the near future.

6. Does her partner have or use a weapon? Has he threatened to kill her? These are not idle threats. The woman must understand that threats of harm or death are good predictors of future behavior. ORIGINS, MYTHS, AND SCIENCE

3. RESEARCH ISSUES AND METHODOLOGY

4.RECOMMENDATIONS

FOREWORD

INTRODUCTION

1. DEFINING THE LINKS

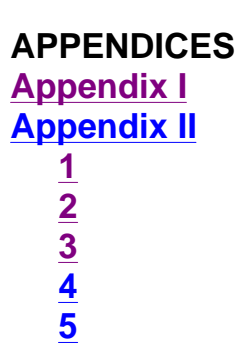

LIST OF

PARTICIPANTS

BIBLIOGRAPHY 
Appendix II

CONFRONTING ABUSE: A GUIDE FOR HEALTH CARE PROVIDERS

Adapted with permission from Marian Sassetti, "Domestic Violence,"

Primary Care: Clinics in Office Practice. 20(2):289-305, 1993.

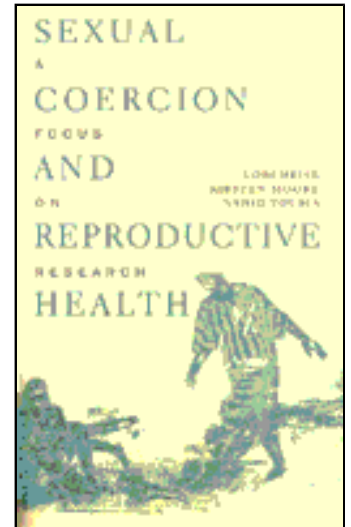

1. Avoid the pitfall of "rescuing." You cannot direct a woman's life or tell her what to do. Remember, she is the expert on her own particular situation. What you can do, is help her see that she does have choices and options, and offer to support her in whatever course of action she chooses to take, including the decision to return to the batterer. Let her know that she is always welcome to come back to you, and avoid judging the choices that she makes.

2. Beware of prescribing psychotropic drugs. Even women who appear to be depressed or otherwise psychologically compromised are often reacting sanely to the insane circumstances of their lives. If you prescribe medication that limits their capacity to react with clarity, you may actually increase the danger that she is in. Most often, battered women are not mentally ill and should not be treated as if they were.

3. Provide her with literature and information about community resources. Contact your local women's crisis center or shelter and familiarize yourself with services available locally for victims of physical or sexual abuse. Always provide the name and number of a local resource group to any woman who discloses, even if she does not express the need for immediate assistance. Consider writing the referral on a business card or prescription pad, so as to not attract attention. Inform her that she may encounter prejudices and difficulties when she attempts to access the resources to which she is entitled, but encourage her to persevere. Without forewarning, she is likely to retreat into hopelessness and inaction if she encounters victim blaming attitudes on the part of social service workers, the police, etc.

4. Clearly document the woman's history and physical findings. Record as many details of the woman's history and physical condition as possible these facts may prove crucial later if she decides to prosecute. Record, for example, "Pt. states she was hit in the face with her partner's fist, punched in the stomach two times, and hit with a screwdriver," or, "Pt. states her husband said he was going to kill her three times." Upon examination you would record "a 3-cm swollen ecchymotic area on the left shoulder, consistent with a wound from a punch, three linear ecchymotic areas on each side of the neck consistent with strangulation marks." Laboratory examinations should be recorded in the same way, even if they yield negative results.
MEN'S VIOLENCE: ORIGINS, MYTHS, AND

SCIENCE

3. RESEARCH ISSUES AND METHODOLOGY

\section{DEFINING THE} LINKS

\section{RECOMMENDATIONS}

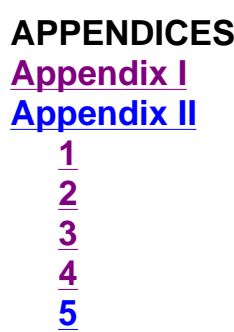

LIST OF PARTICIPANTS

BIBLIOGRAPHY 
Illustrate the location of the injuries on a body map and photograph the injuries, whenever possible.

5. Encourage her to join a support group. Participation in a support group has been shown to have a positive impact on the health and psychological well-being of victims of abuse. Consider making space available in your facility where victims of abuse can meet. 
Appendix II

CONFRONTING ABUSE: A GUIDE FOR HEALTH CARE PROVIDERS

Adapted with permission from Marian Sassetti, "Domestic Violence,"

Primary Care: Clinics in Office Practice. 20(2):289-305, 1993.

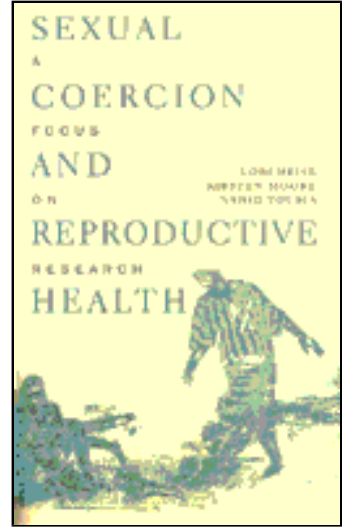

MEN'S VIOLENCE: ORIGINS, MYTHS, AND

3. RESEARCH ISSUES AND METHODOLOGY

4.RECOMMENDATIONS abusive situations and to help them to connect with available services and support.

2. Recognize the good that you have done. You have made an important contribution simply by breaking the silence around abuse. You may well be the first person in this woman's life who has been concerned enough to ask about her well-being.

INTRODUCTION LINKS SCIENCE

FOREWORD

1. DEFINING THE

APPENDICES

Appendix I

Appendix II

$$
\frac{\frac{1}{2}}{\frac{3}{4}}
$$

LIST OF

PARTICIPANTS

BIBLIOGRAPHY 


\section{LIST OF PARTICIPANTS}

\section{BARBARA AGONGA}

ASMA AL'HALEEM

Board Member, Institute for Women, Law and Development

SAJEDA AMIN

The Population Council

ANA AMUCHASTEGUI

MALIKA BEN BARAKA

STEVEN BROWN

\section{NICK DANORTH}

The Pacific Institute for Women's Health

DIANE DI MAURO

Sexuality Research Project,

Social Science Research Council

BARBARA FERINGA

US Agency for International Development

\section{LYNN FREEDMAN}

Reproductive Rights Project,

Development Law and Policy Program, Columbia

University School of Public Health

CHARLOTTE GARDINER

Maternal and Child/Family Planning Program,

Technical and Evaluation Div., UNFPA

\section{ANNIE GEORGE}

LAURA GIBNEY

The Rockefeller Foundation

VIRGINIA GOLDNER

Ackerman Institute for Family Therapy

GILL GORDON

Consultant, IPPF, AIDS Prevention Unit

\section{PENN HANDWERKER}

Anthropology Department

U-1 76, University of Connecticut

\section{SONDRA HAUSNER}

Sexuality Research Assessment

Social Science Research Council

\section{LORI HEISE}

Health and Development

Policy Program

JUDITH HELZNER

International Planned Parenthood Federation,

Western Hemisphere Region

MARGARET HEMPEL

The Ford Foundation

JODI JACOBSON

Health \& Development

Policy Project

\section{MARY KOSS}

Family and Community Medicine

School of Medicine, University of Arizona

\section{INTRODUCTION}

1. DEFINING THE LINKS

2. MEN'S VIOLENCE: ORIGINS MYTHS, AND SCIENCE

3. RESEARCH ISSUES AND METHODOLOGY

4.RECOMMENDATIONS

\section{APPENDICES \\ Appendix \\ Appendix II}

LIST OF

PARTICIPANTS

BIBLIOGRAPHY 
GITA MISRA

The Ford Foundation

KIRSTEN MOORE

Population Council

\section{CHESYAOSIMO MTARIMA}

Research Fellow, Law Department

KATINI NZAU-OMBAKA

NURIYE ORTALI

Istanbul Universitesi Cocuk, Sagligi Enstitusu

PEGGY PENN

Ackerman Institute for Family Therapy

MARIA ISABEL PLATA

Profamilia

ALANAGH RAIKES

Womankind Worldwide

JUAN CARLOS RAMIREZ RODRIQUEZ

Universidad de Guadelajara

\section{VIJAYENDRA RAO}

Department of Economics

Williams College

\section{BETH RITCHIE}

Hunter College

\section{PEGGY SANDAY}

Department of Anthropology, Room 325,

University Museum, University of Pennsylvania

IRMA SAUCEDO

El Colegio de Mexico, A. C.

\section{BERIT SCHEI}

University of Trondheim

Faculty of Medecine,

Dept. of Community Medicine and General Practice

MARCIA SCHEINBERG

Ackerman Institute for Family Therapy

\section{ELIZABETH SCHRADER-COX}

JOSEPHINE SPICEHANDLER

US Agency for International Development

\section{DOROTHY THOMAS}

Human Rights Watch

NAHID TOUBIA

RAINB早

GILLIAN WALKER

Ackerman Institute for Family Therapy

\section{ELLEN WEISS}

International Center for Research on Women

\section{GAIL WYATT}

Neuro-Psychiatric Institute at UCLA 


\section{BIBLIOGRAPHY}

Agger, Inder. 1994. The Blue Room. New Jersey: Zed Books Limited.

Allen, S.M. 1982. "Adolescent pregnancy among 11-15 year old girls in the parish of Manchester." Unpublished Ph.D. dissertation. Kingston: University of the West Indies, as cited in MacCormack, C.P. and A.

Draper. "Social and cognitive aspects of female sexuality in Jamaica." In The Cultural Construction of Sexuality. Ed. P. Caplan. London: Tavistock Publications.

Archer, J. and B. Lloyd. 1985. Sex and Gender, New York: Cambridge, University Press.

Asia Watch, Women's Rights Project. 1993. A Modern Form of Slavery Trafficking of Burmese Women and Girls into Brothels in Thailand. New York: Human Rights Watch.

Bagarukayo, Henry, Dean Shucy, Bernadette Babishangire, Karin Johnson. 1993. An Operational Study Relating to Sexuality and AIDS Prevention among Primary School Students in Kabale District of Uganda. Entebbe: Uganda.

Banwell, Suzanna Stout. 1990. Law, status of women and family planning in sub-Saharan Africa: A suggestion for action. Nairobi: The Pathfinder Fund.

Boyer, D. and D. Fine. 1992. "Sexual abuse as a factor in adolescent prcgnancy and child maltreatment." Family Planning Perspectives 24, $(1): 4$.

Browne, A. and D. Finkelhor. 1986. "The impact of child sexual abuse: A review of the research." Psychological Bulletin. 99:66.

Castelino, C.T. 1985. "Child sexual abuse: A retrospective study." Unpublished manuscript. Tata Institute of Social Sciences, Bombay, India. As cited in U.A. Segal. 1992. "Child abuse in India: an empirical report on perceptions." Child Abuse and Neglect 16:887-908.

Caughey, J.L. 1970. "Cultural values in Micronesian society." Unpublished Ph.D. dissertation, University of Pennsylvania.

Choque, M.E., S. R. Schuler and S. Rance. 1994. "Reasons for unwanted fertility and barriers to use of family planning services among urban Aymara in Bolivia." JSI Working Paper No. 5. Arlington: JSI Research and'Fraining Institute.

Counts, Dorothy Ayers, Judith Brown and Jacquelyn Campbell, eds. 1992. Sanctions and Sanctuary: Cultural Perspectives on the Beating of Wives. Boulder: Westview Press.

deChesney, M. 1989. "Child sexual abuse as an international health problem." International Nurses Review 36, (5):149-15 3.

Denich, B. 1974. "Sex and Power in the Balkans." In Women, Culture, and Society. Michelle Rosaldo and Louise Lamphere, eds. Palo Alto: Stanford University Press.

Donaldson, P.E., M.H. Whalen and JW. Anastas. 1989. "Teen pregnancy and sexual abuse: Exploring the connection." Smith College Studies in Social Work 59, (3):289.

Draaijer, N. 1988. "Intrafamiliar sexual abuse of girls." Ministery of Social Affaires and Labour. The Hague: Vrije Universiteit van Amsterdam.
FOREWORD

\section{INTRODUCTION}

\section{DEFINING THE} LINKS

2. MEN'S VIOLENCE: ORIGINS MYTHS, AND SCIENCE

3. RESEARCH ISSUES AND METHODOLOGY

4.RECOMMENDATIONS

\section{APPENDICES \\ Appendix I \\ Appendix II}

\section{LIST OF \\ PARTICIPANTS}

BIBLIOGRAPHY 
Finkelhor, D., G. Hotaling, I.A. Lewis and C. Smith. 1990. "Sexual abuse in a national survey of adult men and women: Prevalence,

characteristics and risk factors." Child Abuse and Neglect 14, (1):19-28.

Folch-Lyon, E., L. Macorra and S. Bruce Schearer. 1981. "Focus group and survey research on family planning in Mexico." Studies in Family Planning 12, (12):409-32.

Fort, A.L. 1989. "Investigation of the social context of fertility and family planning: A qualitative study in Peru." International Family Planning Perspectives 15, (3):88 - 94.

Gershenson, H., J. Musick, H. Ruch-Ross, V. Magee, K. Rubino and D, Rosenberg. 1989. "The prevalence of coercive sexual experience among teenage mothers." Journal of Interpersonal Violence, 4:2.

Gilmore, D.D. 1990. Manhood in the Making: Cultural Concepts of Masculinity. New Haven: Yale University Press.

Gross, J. 1993. "Where 'Boys Will Be Boys,' and Adults are Befuddled." New York Times. March 29.

Handwerker, Penn. 1993. "Gender power differences between parents and high-risk sexual behavior by their children: AIDS/STD risk factors extend to a prior generation." Journal of Women's Health 2, (3):301.

Harrop-Griffiths, J., W. Katon, E. Walker, L. Holm, J. Russo, and L. Hickok. 1988. "The association between chronic pelvic pain, psychiatric diagnosis, and childhood sexual abuse." Obstetrics and Gynecology 71:589-594.

Haskell, L. and M. Randall. 1993. "The women's safety project: Summary of key statistical findings." Ottawa: Canadian Panel on Violence against Women.

Hegland, Mary. 1993. Personal communication. Santa Clara University, San Jose, California.

Heise, Lori, Jacqueline Pitanguy and Adrienne Germain. 1994, Violence against women: The hidden health burden. Washington, D.C.: The World Bank.

Isis International. 1988. "Campana sobre la violencia en contra de la mujer.' Boletin 16-17, Red de Salud de las Mujeres Latinoamericanas y del Caribe. Santiago: Isis International.

Jahangir, Asma and Jilani, Hina. 1990. A Divine Sanction? Lahore: Rhotas Books.

Kisekka, M.N. and B. Otesanya. 1988. "Sexually transmitted diseases as a gender issue: Examples from Nigeria and Uganda." Paper given at the AFARD/AAWORD Third General Assembly on The African Crisis and Women's Vision of the Way Out. Dakar, Senegal. As cited in $\mathrm{H}$. Standing and M. Kisekka. "Sexual behavior in sub-Saharan Africa: an annotated bibliography." Prepared for the Overseas Development Administration, United Kingdom.

Koss, M.P. and L. Heslet. 1992. "Somatic consequences of violence against women." Archives of Family Medicine 1: 53.

Lancaster, R.N. 1992. Life is Hard: Machismo, Danger, and the Intimacy of Power in Nicaragua. Berkeley and Los Angeles: University of California Press.

Levinson, David. 1989. Violence in Cross-Cultural Perspective. Newbury Park: Sage.

Lewis, I.A. 1985. Unpublished raw data from Los Angeles Times poll \#98. As cited in Finkelhor, D. A Sourcebook on Child Sexual Abuse. Newbury Park: Sage.

Lieberman, M.A. and L.D. Borman. 1979. Self-help groups for coping with crisis: Origins, members, processes and impact. San Francisco: Jossey-Bass. 
Lieberman, M.A. and L. Videka-Sherman. 1986. "The impact of self-help groups on the mental health of widows and widowers." American Journal of Orthospychiatrica 36:435-449.

Maccoby, Eleanor. 1980. Social Development: Psychological Growth and the Parent-Child Relationship. New York: Harcourt Brace Jovanovich.

Marcus, M. 1987. "Horsemen are the fence of the land: Honor and history among the Ghiyata of Eastern Morocco." In Honor and Shame and the Unity of the Mediterranean. D.D. Gilmore, ed. Washington D.C.: American Anthropological Association, Special Publication No.22.

Marshall, M. 1979. Weekend Warriors. California: Mayfield.

Martin, J., J. Anderson, S. Romans, P. Mullen and M. O'Shea. 1993. "Asking about child sexual abuse: Methodological implications of a two stage survey." Child Abuse and Neglect 17:383-392.

Meursing, Karla. 1993. Child Sexual Abuse in Matabeland. Bulawayo, Zimbabwe: Matabeland AIDS Council.

Miedzian, Myriam. 1991. Boys Will Be Boys: Breaking the Link Between Masculinity and Violence. New York: Doubleday.

Ofboagyc, Rosemary Ofeibea. 1994. "Domestic violence in Ghana: An initial step." Columbia Journal of Gender and Law 4(I):1-25.

Okongo, 1991. As cited in Olowo-Freers, Bernadette P.A. and Thomas G. Barton. 1992. In Pursuit of Fulfillment: Studies of Cultural Diversity and Sexual Behaviour in Uganda. Marianum Press.

Profamilia. 1992. "Estudio sobre la violencia contra la mujer en la familia basado en la encuesta realizada a las mujeres maltratadas que acudieron al Servicio Juridico de ProFamilia entre el 15 de Marzo de 1989 y el 30 de Marzo de 1990." In La Violencia y Los Derechos Humanos de la Mujer. Bogota: Profamilia.

Rance, Susanna: 1994. "Control and Resistance: Empowering Strategies in the Reproductive Lives of La Paz Market Women." Empowerment of Women Research Program, Bolivia Report No. 1. Arlington: JSI Research and Training Institute.

Reiter, R.C., L.R. Shakerin, J.C. Gambone and A.K. Milburn. 1991. "Correlation between sexual abuse and somatization in women with somatic and nonsomatic chronic pelvic pain." Obstetrics and Gynecology 75:428.

Riggs, A., A.J. Alario, and C. McHorney. 1990. "Health risk behaviors and attempted suicide in adolescents who report prior maltreatment." Journal of Pediatrics 116 (5):815.

Rosas, M. Isabel. 1992. "Violencia sexual y politica criminal." Lima, Peru: Comite Latinoamericano para la Defensa de las Dereches de la Muier, (CLADEM), Informativo 6.

Rozee, P.D. 1993. "Forbidden or forgiven?: Rape in cross-cultural perspective." Psychology of Women Quarterly 17:499-514.

Sanday, Peggy Reeves. 1981, "The socio-cultural context of rape: A cros , cultural study." Journal of Social Issues 37 (4):5-27.

Schei, B. and L.S. Bakketeig. 1989. "Gynecological impact of sexual and physical abuse by spouse: A random sample of Norwegian women." Britis), Journal of Obstetrics and Gynecology 96 (12):1379-1382.

Schei, B. 1990. "Prevalence of sexual abuse history in a random sample of Norwegian women." Scandinavian Social Medicine 18 (1):63-68.

Schei, B. 1990. "Psycho-social factors in pelvic pain: A controlled study of women living in physically abusive relationships." Acta Obstetrics and Gynecology Scand, 69 (1):67-7 1. 
New Jersey: Rutgers University Press.

Simon, R.J. and S. Baxter. 1989. "Gender and violent crime." In Violent Crime, Violent Criminals. Weiner, N.A. and M.E. Wolfgang, eds.

London: Sage.

Stoltenberg, J. 1989. Refusing to Be A Man: Essays on Sex and Justice. Oregon: Breiten Bush Books.

Toseland, R.W., C. M. Rossiter, T. Peak and P. Hill. 1990. "Therapeutic processes in peer led and professional led support groups for caregivers." International Journal of Group Psychotherapy 40 (3):279303.

Turner, Angela K. 1994. "Genetic and Hormonal Influences on Male Violence." In Male Violence, John Archer, ed. New York and London: Routledge.

Walker, E., W. Katon, K. Neraas, R. Jemelka and D. Massoth. 1992. "Dissociation in women with chronic pelvic pain." American journal of Psychiatry 149 (4):5 34.

Walker, S., S. Granthan-McGregor, J.H. Himes, and S. Williams. 1994. Nutritional and Health Determinants of School Failure and Dropout Adolescent Girls in Kingston, Jamaica. Washington, DC: International Center for Research on Women. Nutrition of Adolescent Girls Research Program, No. 1.

Wood, D.P., M.G. Wiesner, and R.C. Reiter. 1990. "Psychogenic pelvic pain: Diagnosis and management." Clinical Obstetrics and Gynecology 33:179.

Zierler, S., L. Feingold, D. Laufey, P. Velentgas, 1. KantrowitzGordon and K. Mayer. 1991. "Adult survivors of childhood sexual abuse and subsequent risk of HIV infection." American Journal of Public Health 81 (5):572. 